\title{
Investigation of Sentinel-1 Derived Land Subsidence Using Wavelet Tools And Triple Exponential Smoothing Algorithm In Lagos, Nigeria
}

Femi Emmanuel Ikuemonisan ( $\square$ femi.ik@yahoo.com )

University of Lagos Faculty of Science https://orcid.org/0000-0002-1671-8733

Vitalis Chidi Ozebo

University of Lagos Faculty of Science

Olawale Babatunde Olatinsu

University of Lagos Faculty of Science

\section{Research Article}

Keywords: Triple Exponential smoothing, Wavelet analysis, Land subsidence, Temporal evolution, Prediction.

Posted Date: September 8th, 2021

DOl: https://doi.org/10.21203/rs.3.rs-170400/v1

License: (c) (i) This work is licensed under a Creative Commons Attribution 4.0 International License. Read Full License 
Investigation of Sentinel-1 derived land subsidence using wavelet tools and triple exponential smoothing algorithm in Lagos, Nigeria

Femi Emmanuel Ikuemonisan*, Vitalis Chidi Ozeboํㅜ, Olawale Babatunde Olatinsu ${ }^{1}$

${ }^{1}$ Department of Physics, Faculty of Science, University of Lagos, Akoka, Lagos, Nigeria

* Corresponding author

femi.ik@yahoo.com (F.E. Ikuemonisan), orcid.org/0000-0002-1671-8733

cozebo@unilag.edu.ng (V.C. Ozebo)

oolatinsu@unilag.edu.ng (O.B. Olatinsu) 


\begin{abstract}
Lagos has a history of long-term groundwater abstraction that is often compounded by the rising indiscriminate private borehole and water well proliferation. This has resulted in various forms of environmental degradation, including land subsidence. Prediction of the temporal evolution of land subsidence is central to successful land subsidence management. In this study, a triple exponential smoothing algorithm was applied to predict the future trend of land subsidence in Lagos. Land subsidence time series is computed with SBAS-InSAR technique with Sentinel-1 acquisitions from 2015 to 2019. Besides, Matlab wavelet tool was implemented to investigate the periodicity within land displacement signal components and to understand the relationship between the observed land subsidence, and groundwater level change and that of soil moisture. Results show that land subsidence in the LOS direction varied approximately between -94 and $15 \mathrm{~mm} / \mathrm{year}$. According to the wavelet-based analysis result, land subsidence in Lagos is partly influenced by both groundwater level fluctuations and soil moisture variability. Evaluation of the proposed model indicates good accuracy, with the highest residual of approximately 8\%. We then used the model to predict land subsidence between the years 2020 and 2023 . The result showed that by the end of 2023 the maximum subsidence would reach 958 mm which is approximately $23 \%$ increase.
\end{abstract}

Keywords: Triple Exponential smoothing; Wavelet analysis; Land subsidence; Temporal evolution; Prediction. 


\section{$1 \quad$ Introduction}

Rapid population expansion combined with rising day-to-day commercial activities often create different forms of interactions between humans and the environment, including the ground surface. These interactions usually impact the natural evolution of the landscape and physical processes. The impacts of such interactions are evident in Lagos metropolis. The long-term excessive groundwater abstraction compounded by the indiscriminate private borehole and water well proliferation (NERC, 2003; Oyeyemi et al., 2015), has resulted in various forms of environmental degradation, including flooding, coastal erosion, and land subsidence. Land subsidence is an irreversible downward displacement of the earth's surface that can potentially, and perhaps permanently, deform the affected areas if inadequately monitored (Zeitoun et al., 2013), making it a treat to environmental sustainability. Land subsidence is particularly problematic when

the ground under a physical structure is undergoing differential settling. Land subsidence of devastating proportion has been reported in several parts of Lagos metropolis (Cian et al., 2019; Ikuemonisan et al., 2020), with impacts ranging from the collapse of foundation structure to coastal erosion and inland sea water intrusion, among others. All of which translates to major financial losses. Therefore, timely monitoring and prediction of the temporal evolution of land subsidence are important to the attainment of a sustainable environment because it will help to mitigate and prevent land subsidence and subsidence induced hazards.

Excessive ground fluid withdrawal has been reported in several kinds of literatures as a major triggering factor for land subsidence (Hu et al., 2014; Abidin et al., 2015). In Lagos, almost every household has at least a private borehole and/or a water well for the purposes of domestic consumptions. The rising number of manufacturing industries in and around the metropolis also heavily impacts the groundwater level fluctuations, manifesting direct consequence in the form of land subsidence (Cian et al., 2019). Furthermore, the increasing rate of reclamation of coastal areas is an equally verified reason for a widespread land subsidence in parts of the Lagos metropolis (Olatinsu et al., 2018). Several attempts made by the regulatory authorities to regulate groundwater abstraction in Lagos were often confronted with stiff resistance by the inhabitants for many reasons, including poor public water supply system (Balogun et al., 2016).

In the past, different monitoring methods have been used by various authors to study land subsidence in Lagos. These include persistent scatterer synthetic aperture radar (PS-InSAR) analysis (Cian et al., 2019), small baseline subset interferometric (SBAS-InSAR) analysis (Ikuemonisan and Ozebo, 2020) and geostatistical modelling (Ikuemonisan et al., 2020). Some of the existing studies concentrate only on the contribution and response of groundwater abstraction to land subsidence. While a few others focus on the impacts of land subsidence on Lagos infrastructure and the spatial variability of subsidence rate. In all the existing studies, restricted attention is given to the prediction of future scenarios 
of land subsidence. Nevertheless, accurate monitoring and prediction of land subsidence are essential for urban planning and risk assessment.

Although several studies demonstrate that InSAR technology has the capability to accurately monitor land displacement over a wide area at high spatial resolution (Hu et al., 2014; Chen et al., 2017), InSAR technology uses historical observations to reveal temporal evolution but is insufficient to predict future scenarios of land deformation. This underscores the need for an integration of InSAR results and time series modelling techniques to predict future scenarios. Against this background, this research is aimed at predicting the temporal evolution of land subsidence in the Lagos metropolis by integrating SBAS-InSAR results and the triple exponential algorithm. In addition, wavelet analysis was performed to establish physical relationship between land subsidence, and groundwater level changes and soil moisture variability. For the first time, this study presents the future trend of land subsidence in Lagos and establishes the correlation between land subsidence and groundwater level changes and soil moisture variability. With the wavelet tools, this study also investigated the periodicity of land subsidence and groundwater level changes. Wavelet is a time series processing tool that can be used to study temporal patterns in non-stationary phenomena (Torrence and Compo, 1998). Wavelet is particularly useful for extracting attributes from time series data with a low signal-to-noise ratio and for identifying localized intermittent periodicities that affect land deformation dynamics (Grinsted et al., 2004).

There are various types of subsidence modelling methods. These include time series modelling, which has been classified by various authors (Deng et al., 2017; Shrestha et al., 2017; Bagheri et al., 2019). The time series modelling method can be classified into the theory-based model and the data-based model. The data-based model is generally referred to as empirical model. The theory-based time series model involves the study of the system's internal dynamics and the various driving mechanisms to provide a mathematical representation of the objective physical phenomenon. Although theoretical models can be used to model and predict the temporal evolution of land subsidence, the possibility to accurately model land subsidence is mostly hindered by inadequate information on the hydrogeological parameters describing the aquifer system of the objective area. Also, regular monitoring of land subsidence on a regional scale is computationally expensive. The inconsistency in the data collected by various satellite missions equally makes the analytical investigation of land subsidence more problematic.

On other hand, the data-based model uses mathematical formulations derived from the observation data to predict future values. It is useful when the various factors triggering the phenomenon under investigation cannot be easily accounted for (Deng et al., 2017). Ikuemonisan et al. (2020) attributed land subsidence in Lagos to various causes, which include 
over-exploitation of groundwater, oxidation of peatland, and decomposition of organic matter. These factors cannot be easily modelled by physical models, thus making an empirical time series model a conceivable alternative method to accurately model land subsidence in Lagos. The empirical model has been widely used to monitor future scenario of timevarying phenomena. In this study, an empirical model method, known as the triple exponential smoothing, is used to model and predict the temporal evolution of land subsidence in the Lagos metropolis. Triple exponential smoothing algorithm (also known as Holt Winter model) has been successfully used to predict future scenarios of time series variables (Yang et al., 2017). Triple exponential smoothing can manage time series data with trends and seasonal changes, in addition to random fluctuations and error terms.

\section{Geographical and geological setting of the study area}

Administratively, the name Lagos is used for both a State and a metropolis. Metropolitan Lagos is an area of land around the Lagos harbor (Longe et al., 1987), and it is our study area in the present study. Metropolitan Lagos is approximately bounded between latitudes $\left(6.4^{\circ}-6.7^{\circ}\right) \mathrm{N}$ and longitudes $\left(3.1^{\circ}-3.7^{\circ}\right)$ E. Geologically, it is situated within a zone of coastal creeks and lagoons, largely enclosed by the Lagos lagoon system created by boundary breaches linked to sand deposits (Hill and Webb, 1958). The study area is underlain by sedimentary deposits of coastal plain sand, generally known as the Benin Formation. The coastal plain sand consists mainly of sand, silt and clay, with a multi-aquiferous succession featuring alternating sand and clay layers (Ayolabi and Peter, 2005). 


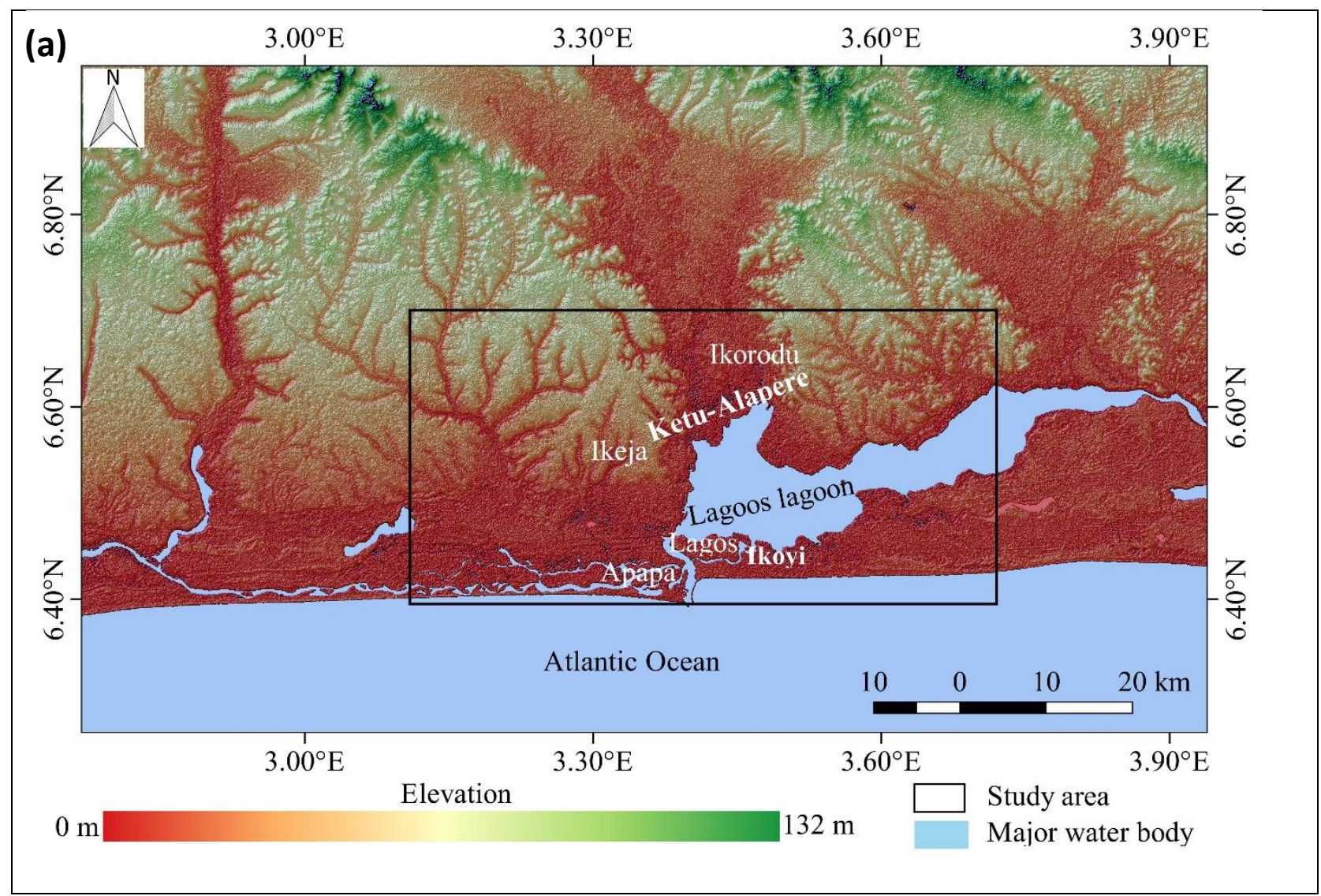

Fig. 1 Map of the study area. (a): digital elevation map of Lagos State with the study area enclosed in the black rectangle.

The coastal plain sand is an outcropping formation overlying the Ilaro and Ewekoro Formations and the Abeokuta Group in the mainland area. Three primary aquifers are identified within the basin and are characterised as follows (KampsaxKruger and Sshwed Associates, 1977): recent sediments, coastal plain aquifer, and Abeokuta Formation. The recent sediments layer forms the surface aquifer and is dominant within the coastal plain sands, while the most abundant aquifer is found within the Abeokuta Group. The topography of Lagos is generally low-lying, flat in most parts with several points at sea level, thus exposing the area to prevalent seasonal flooding. The map of the study area is shown in Fig. 1.

Detailed descriptions of Lagos surface geology have been reported in the literature (e.g., Olowofela et al., 2012). Metropolitan Lagos occupies an area of about $1,171 \mathrm{~km}^{2}$, yet it is one of the most populated cities in Africa, with a current population of approximately 25 million inhabitants and $4 \%$ annual growth. Due to its proximity to the Atlantic Ocean and the abundance of coastal resources and coupled with its status as the country's former capital, Lagos has witnessed a dramatic population increase in recent years. To manage this growing population, government and private sectors are embarking on massive infrastructural development such as roads, rain tracks, event centers, shopping malls, schools, 
residential and industrial estates all of which underscore the possibility of over-dependence on the available groundwater resource and increasing demand for land reclamation.

\section{Methods and data used in this study}

\subsection{Data Source}

This section presents an overview of the research method and the datasets. The approach considered in this study was a hybrid technique involving wavelet analysis and triple exponential smoothing algorithm. The data used were obtained from three major sources: Sentinel-1 (land subsidence), Gravity Recovery And Climate Experiment (GRACE), for groundwater level changes; and Global Land Data Assimilation System (GLDAS) for soil moisture. Groundwater level changes (Landerer and Swenson, 2012) and soil moisture datasets (Rodell et al., 2004) corresponding to conceivable triggering factors and the third dataset corresponding to the displacement time series of the InSAR derived land subsidence, which were used as input variables in the proposed model.

\subsection{Theoretical background}

The SBAS-InSAR technique is a method for generating surface deformation from InSAR time series using interferometric pairs of small temporal gap baselines. SBAS-InSAR has been successfully used in land subsidence monitoring (Zhang et al., 2019; Zhou et al., 2017). The method of processing of SABS-InSAR can be classified into four main steps. These include selection of short spatial-temporal baseline, interference management based on the given baseline subsets, retrieval of unwrap deformation phase, and separation of the error component of the unwrapping phase in order to generate actual deformation. The atmospheric artifacts are removed by the application of low pass filtering procedure in the 2D spatial domain and then by a temporal high pass filtering. Although a detailed theoretical framework for SBASInSAR analysis has been reported in previous literature (Berardino et al., 2002), for the sake of correctness only the overview is highlighted in this paper. The principle of SBAS-InSAR is based on Equation 1. Given the quantity range of M differential interferograms (phase difference between co-registered images) generated by $\mathrm{N}+1 \mathrm{SAR}$ images at the same area with ordered time $\left(\mathrm{t}_{0}, \mathrm{t}_{1}, \mathrm{t}_{2} \ldots, \mathrm{t}_{\mathrm{N}}\right)$, it can be expressed that:

$$
\frac{N+1}{2} \leq M \leq N\left(\frac{N+1}{2}\right)
$$

Where $\mathrm{N}$ is the number of SAR images. Given any two differential interference interferograms $\left(t_{b}>t_{a}\right)$, the phase difference between two co-registered images can be expressed as:

$$
\phi_{x, i}=\phi_{f l a t, x, i}+\phi_{\text {displ }, x, i}+\phi_{\text {elev }, x, i}+\phi_{a t m, x, i}+\phi_{\text {noise }}
$$




$$
\delta \phi=\phi_{x, t(b)}-\phi_{x, t(a)}
$$

Where $\phi_{x, i}$ is the $i$ SAR image and the interference phase of the $x$ pixel. $\delta \phi$ is the phase difference between two registered SAR images. $\phi_{x,(t b)}$ and $\phi_{x,(t a)}$ are the interference phases at two different times. $\phi_{\text {flat }, x, i}, \phi_{\text {displ, }, i}, \phi_{\text {elev }, x, i}$, $\phi_{a t m, x, i}, \phi_{\text {noise }}$ are the phase difference for flat phase, ground displacement phase, terrain phase, atmospheric phase, and error phase, respectively. The respective phase can be obtained as follows:

$$
\begin{gathered}
\phi_{\text {flat }, x, i}=-\frac{4 \pi}{\lambda} \frac{B_{\perp}}{R \tan \theta} \\
\phi_{\text {displ }, x, i}=\Delta \phi_{i}(\mathrm{x}, \mathrm{r})=\frac{4 \pi}{\lambda}\left[\phi\left(t_{b}, x, r\right)-\phi\left(t_{a}, x, r\right)\right] \\
\phi_{\text {elev }, x, i}=-\frac{4 \pi}{\lambda} \frac{\Delta q}{\sin \theta} \frac{B_{\perp}}{R} \\
\phi_{a t m, x, i}=\phi_{a t m,}\left(t_{b} x, r\right)-\phi_{a t m,}\left(t_{a}, x, r\right)
\end{gathered}
$$

Where $B_{\perp}$ is the vertical baseline, $\Delta q$ is the digital elevation model difference, $R$ is the distance along LOS, $\phi\left(t_{i}, x, r\right)$ is the unknown phase of the image involved in the interferogram generated between the time $t_{b}$ and $t_{a},(x, r)$ is the pixel of range and azimuth coordinates, $\phi\left(t_{a}, x, r\right)$ and $\phi\left(t_{b}, x, r\right)$ are the radar line-of-sight (LOS) of the cumulative deformation at time $t_{a}$ and $t_{b}$, respectively. $\lambda$ is the radar wavelength. The incremental displacement can be expressed as:

$$
\phi_{d i s p l, x, i}=\frac{4 \pi}{\lambda} \sum_{i=t_{a}}^{t_{b}} v_{i, i+1}\left(t_{i+1}-t_{i}\right)
$$

where $v_{i}(i=1, \ldots \ldots, n)$ is the deformation rate in the time interval between two interferograms. Thus, the SBAS-InSAR technique generates displacement multi-temporal time series for each pixel.

\subsection{Sentinel-1 Data Processing}

SBAS-InSAR's ability to accurately monitor land subsidence and generate cumulative ground displacement resulting from various triggering factors has already been verified (Chen et al., 2017; Scifoni et al., 2016). To understand the land subsidence history of our study area, LOS displacement (land subsidence time series) was generated by processing a total of 135 archived Sentinel-1 images acquired on ascending orbits (Track 1) from 2015 to 2019. The processing was performed using the SBAS-InSAR service of the Geohazards Exploitation Platform (GEP), which is a web-based platform developed to support the exploitation of satellite Earth Observation (EO) for the purpose of monitoring geohazards. Through the GEP's SBAS-InSAR service, a multitemporal InSAR analysis via the Parallel SBAS (P-SBAS) algorithm (Berardino et al., 2002; Casu et al., 2014; De Luca et al., 2015) was performed. 


\subsection{Wavelet-based analysis of InSAR, moisture, and groundwater time series}

Continuous wavelet transform (CWT) is a useful tool for expanding time series data into two-dimensional time-frequency space and identifying localized regular periodicities within a time series (Grinsted et al, 2004). CWT has been successfully applied to analyse geophysical time series data. To successfully implement CWT, the time-series input parameters need to be regularly spaced in time (Tomás et al., 2016). Sentinel-1A satellite has a revisit time of 12 days, which makes CWT a suitable tool to analyse the Sentinel-1 SBAS-InSAR derived vertical deformation time series without further transformation. SBAS-InSAR analysis usually estimates ground displacements as a combination of both linear and nonlinear components. While the linear component indicates a continuous period over time in the frequency domain, the nonlinear component, on the other hand, may include different periods with higher frequency patterns at different time intervals, including seasonal variations.

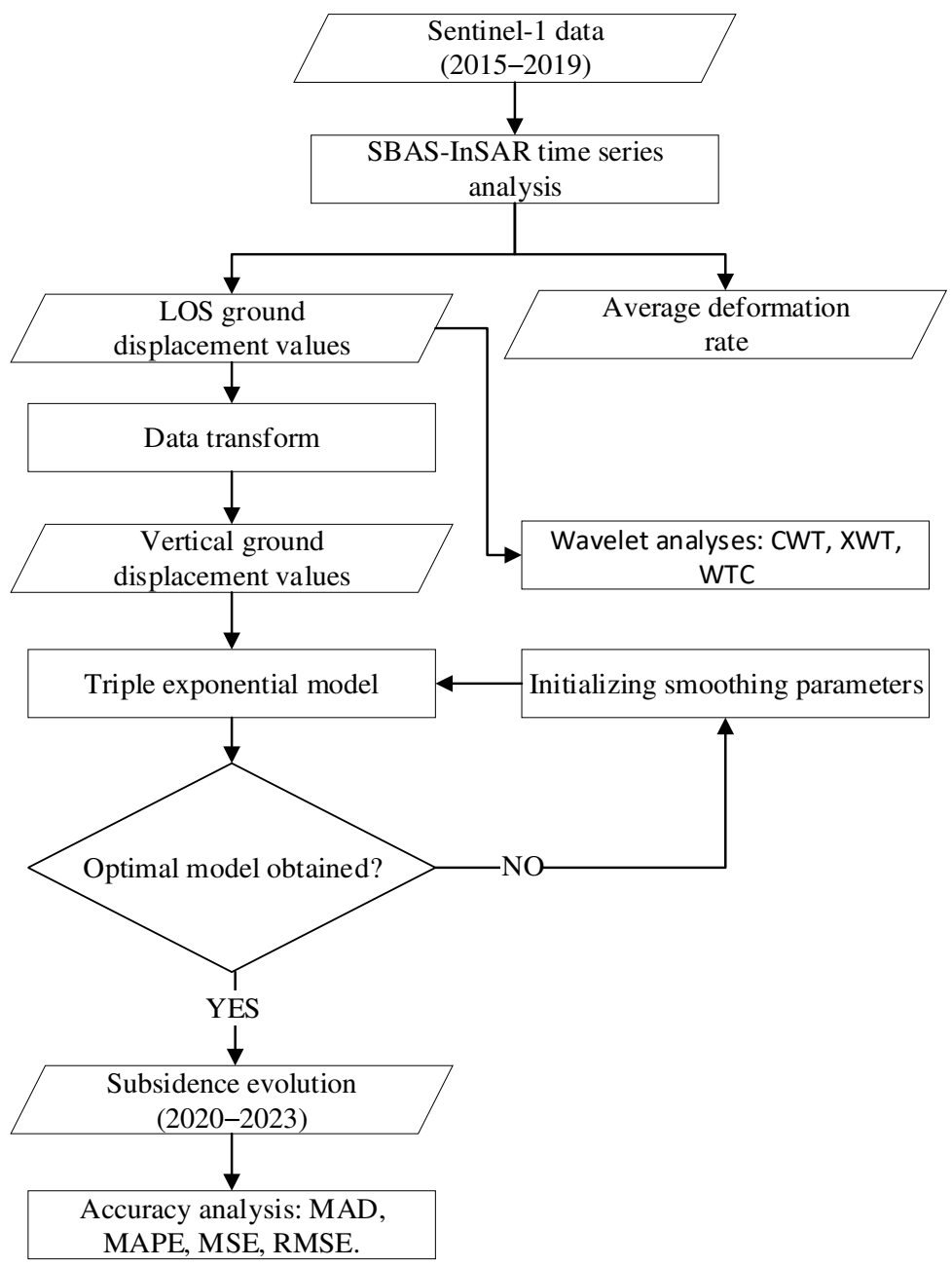

Fig. 2 Work flow of methodology used in the study 
However, to investigate the physical relationship between the two different time series of interest, cross wavelet transform (XWT) and wavelet transform coherence (WTC) tools were used. The XWT analysis provides a two-dimensional representation of the absolute value and the phase of the complex number in the time-frequency space, which can be used to identify similarities in the trend of the two time series data. XWT computes the CWT of the time series and the complex conjugate of the other time series and multiplies the two results, detecting regions characterised by high common timelocalized oscillations. In contrast, WTC calculates the coherence of the two time series regardless of the magnitude of the common power to show the correlation within a local phase. The phase of the XWT shows the presence of time lag between the two time series. For instance, $0^{\circ}$ implies that the two time series are in-phase or in temporally coincidence; approximately $-/+180^{\circ}$ indicates anti-phase or temporally inverse). In this study, the cross wavelet and wavelet coherence toolbox (Grinsted et al., 2004), a Matlab toolbox, was used to analyse SBAS-InSAR land subsidence time series, and the correlation between the groundwater level changes and soil moisture variability. The wavelet toolbox can be assessed at http://www.glaciology.net/wavelet-coherence. Prior to the wavelet analysis, the groundwater level changes time series and soil moisture time series were interpolated to make them temporally consistent with the dense InSAR time series. The key components of the wavelet tools utilized in this research are presented in Table $\mathbf{1 .}$

Table 1 Overview of wavelet tools components (Tomás et al., 2016)

\begin{tabular}{cccccc}
\hline S/N & Tool & $\begin{array}{c}\text { No. of } \\
\text { required } \\
\text { time series }\end{array}$ & Magnitude connotation & Phase interpretation & Resolution type \\
\hline 1 & CWT & 1 & Time patterns resent & - & Original \\
2 & XWT & 2 & $\begin{array}{c}\text { Time patterns with large } \\
\text { power in both time-series }\end{array}$ & $\begin{array}{c}\text { Presence of time lag } \\
\text { between both series }\end{array}$ & Original \\
3 & WTC & 2 & $\begin{array}{c}\text { Similar time patterns in } \\
\text { both time-series }\end{array}$ & $\begin{array}{c}\text { Presence of time lag } \\
\text { between both series. }\end{array}$ & Degraded \\
\hline
\end{tabular}

\subsection{Triple exponential model}

Considering that the land subsidence dynamics is a complex response to several triggering factors, time series analysis can provide useful information on the combined impact of various triggering factors. A triple exponential algorithm is a powerful tool for analysing and forecasting land subsidence because it is capable of managing various components of a time series data. The basic idea behind the triple exponential algorithm technique is to decompose a time series into various components: linear trend, seasonal, and random change. Once the trend, incremental, and seasonal changes are computed, a predictive model is defined to extrapolate the predicted value. The principle of triple exponential smoothing 
is stated below. For the original time series determined by $\operatorname{SBAS}-\operatorname{InSAR} y(t)^{0}=y^{0}(1), y^{0}(2), y^{0}(3)$, $y^{0}(4), \ldots, y^{0}(n)$ the exponential triple model can be expressed as:

$$
\begin{gathered}
\mathrm{L}_{\mathrm{t}}=\alpha \frac{y_{t}}{S_{t-1}}(1-\alpha)\left(\mathrm{L}_{\mathrm{t}-1}+T_{\mathrm{t}-1}\right) \\
T_{\mathrm{t}}=\beta\left(\mathrm{L}_{\mathrm{t}}-\mathrm{L}_{\mathrm{t}-1}\right)+(1-\beta) T_{\mathrm{t}-1} \\
\mathrm{~S}_{\mathrm{t}}=\gamma \frac{y_{t}}{L_{t}}(1-\gamma) \mathrm{S}_{\mathrm{t}-1}
\end{gathered}
$$

Where $y_{t}$ is the observed vertical displacement (subsidence or uplift), $L_{t}$ is the level (average value), $T_{t}$ is the trend, $S_{t}$ is the seasonality, $\alpha, \beta$ and $\gamma$ are smoothing coefficients for level, trend, and seasonality, respectively. Accordingly, the prediction is obtained as follows:

$$
P_{t+k}=\left(L_{t}+k T_{t}\right) S_{t-1+k}
$$

where $\mathrm{k}$ is the length of the seasonal cycle, known as the time intervals from the moment to the predicted time.

\section{Results and Discussion}

\subsection{Sentinel-1 derived surface displacement}

To investigate the spatiotemporal evolution of land subsidence in Lagos, for the period of 2015-2019, SBAS-InSAR technique was employed to detect surface deformation. The time series for Sentinel-1 retrivals based on the method described in Sections 3.2 and 3.3 was generated. Interferograms of the Sentinel-1 SAR stack provided good coverage for the entire study area, excluding the vegetative, watershed, and water areas. A total of 187,115 deformation data points were revealed by the SBAS-InSAR analysis. The SBAS-InSAR results revealed that the average subsidence rates in the LOS direction ranged between $-94 \mathrm{~mm} /$ year to $15 \mathrm{~mm} /$ year for the period of $2015-2019$. 


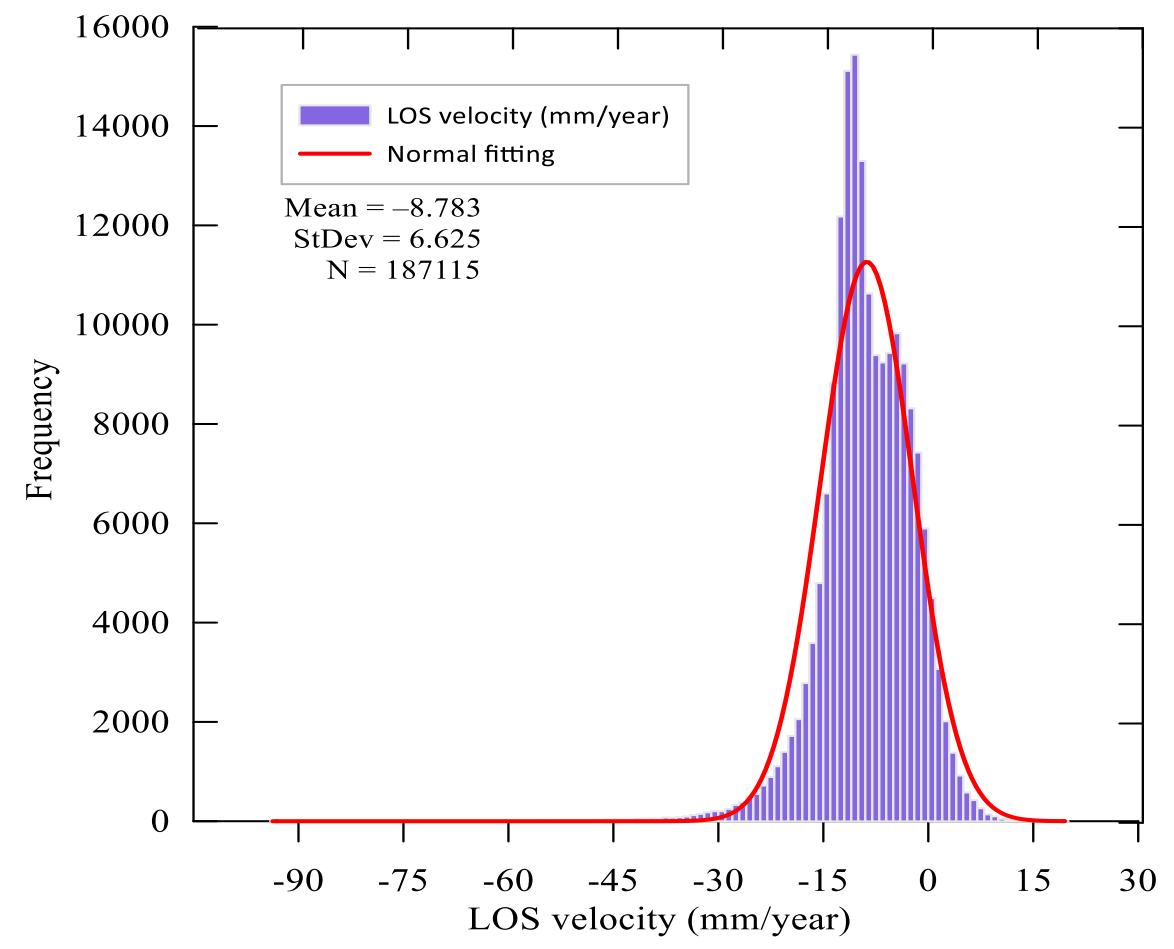

Fig. 3 Histogram of Sentinel-1 measured land subsidence over the study area (After Ikuemonisan et al., 2021)

Fig. 3 shows the histogram of the subsidence rates in the study area. As can be seen in Fig. 3, the histogram is strongly negatively skewed, indicating that some parts of the study area exhibit high subsidence rates reaching about -94 $\mathrm{mm} / \mathrm{year}$ at the end of 2019. The average subsidence rate for the entire study area is approximately $-8.7 \mathrm{~mm} / \mathrm{year}$. Fig. 4 is a map describing the mean LOS velocity of the study area. In the figure, negative and positive values respectively represent subsidence and uplift rates Accordingly, based on the equation of transformation scenario (vertical displacement $=\frac{\text { Los displacement }}{\cos \theta}$, where $\theta$ is the radar incidence angle), the vertical displacement for the same period ranged from $-115 \mathrm{~mm} /$ year to $18 \mathrm{~mm} /$ year. Kriging interpolation was adopted to predict deformation values for the locations not determined by the SBAS-InSAR analysis. The result of the interpolation is shown in Fig. 5. The kriging result indicates that the maximum subsidence is dominant in the coastal zones, watershed, and plains areas. Areas where heavy structures are built on unconsolidated sediments are also found to exhibit considerable high subsidence rate, as corroborated by site inspection. 


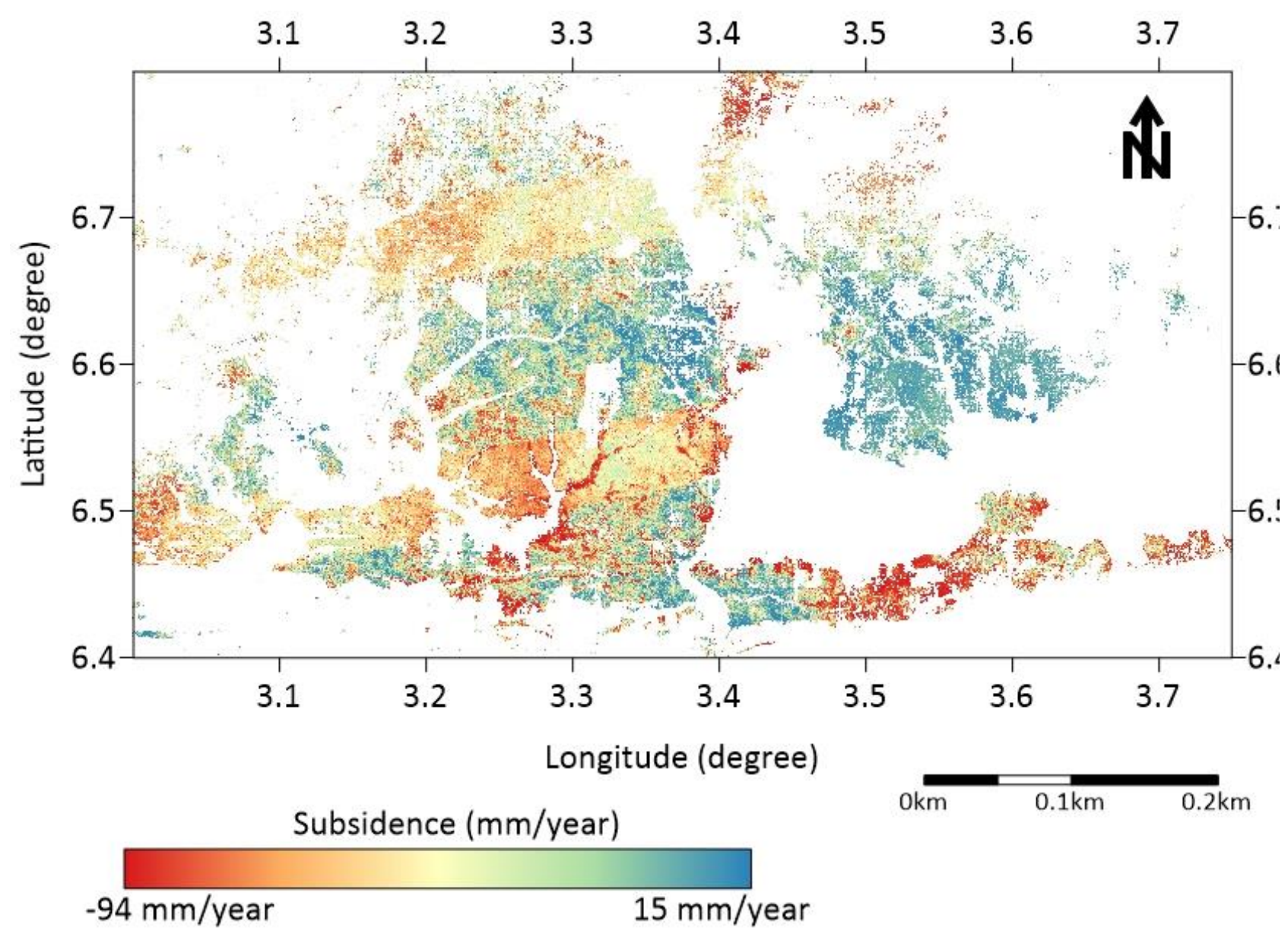

Fig. 4 Mean LOS velocity maps generated through the SBAS-InSAR processing for Sentinel-1 data acquired between 2015 and 2019. Areas of no data (white background) indicate major water body and/or vegetation 


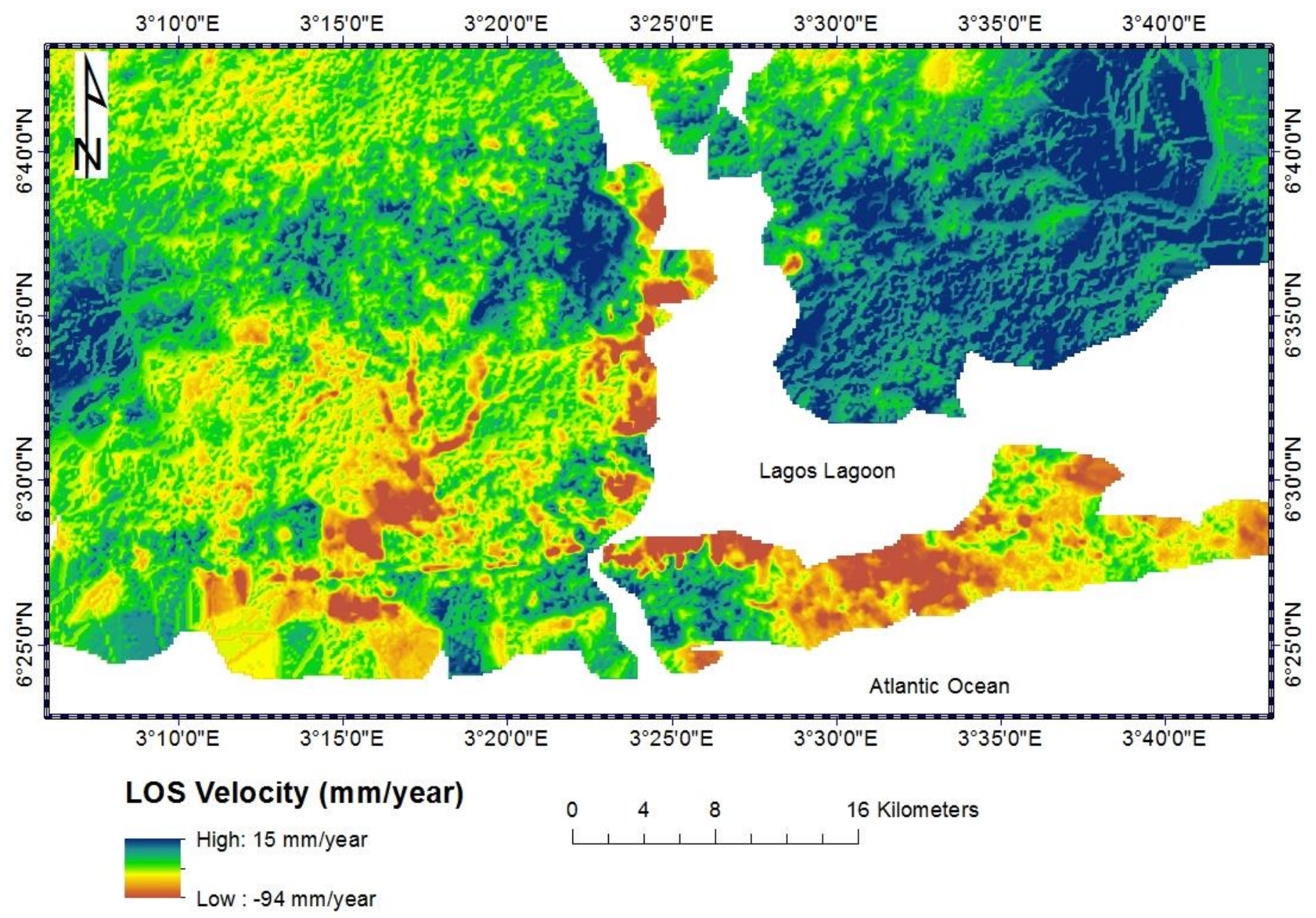

Fig. 5 Mean vertical LOS deformation velocities obtained by kriging interpolation applied to SBAS-InSAR retrievals acquired between 2015 and 2019

The time series of vertical displacement typically showed a steady evolutional trend for all subsiding areas but at different rates, as shown in Fig. 6. Most of the subsidence observed in Lagos indicated a slight oscillatory trend, which may be an indication of progressive groundwater abstraction combined with seasonal factors (such as rainfall) in most parts of the study area. Fig. 6 shows the vertical displacement time series for points where maximum subsidence rates were observed. The coordinates of the points of maximum land subsidence rates are shown in Fig. $\mathbf{6 b}$. As can be seen in Fig. $\mathbf{6 b}$, the locations of the 36 time series are generally found around/along the coastal lines, which are classified as alluvial deposits (Ikuemonisan et al, 2021). Thus, the observed high subsidence rate in these areas is attributable to rapid compaction of unconsolidated sediments and/or poroelastic response of the aquifer systems to groundwater redistribution. Fig. 7 shows the cumulative subsidence map for the study area. From the figure, it is shown that spatial distribution of land subsidence in most parts of Lagos is general uneven. This suggests that the distribution of and evolution of land subsidence in Lagos are driven by its subsurface geology structures and land use characteristics, including high rate of groundwater 
exploitation and land reclamation. The areas of high subsidence rates include Ikoyi, Eti-Osa, Surulere, Kosofe, Oshodi, Ajeromi Ifelodun, and Mushin. Parts of Ikorodu and parts of Isheri Olofin also show significantly high subsidence rates. On the other hand, most parts of Ikeja and Alimosho are relatively stable, with uplift of approximately $15 \mathrm{~mm} / \mathrm{year}$ observed in parts Ikeja and Alimosho.

(a)

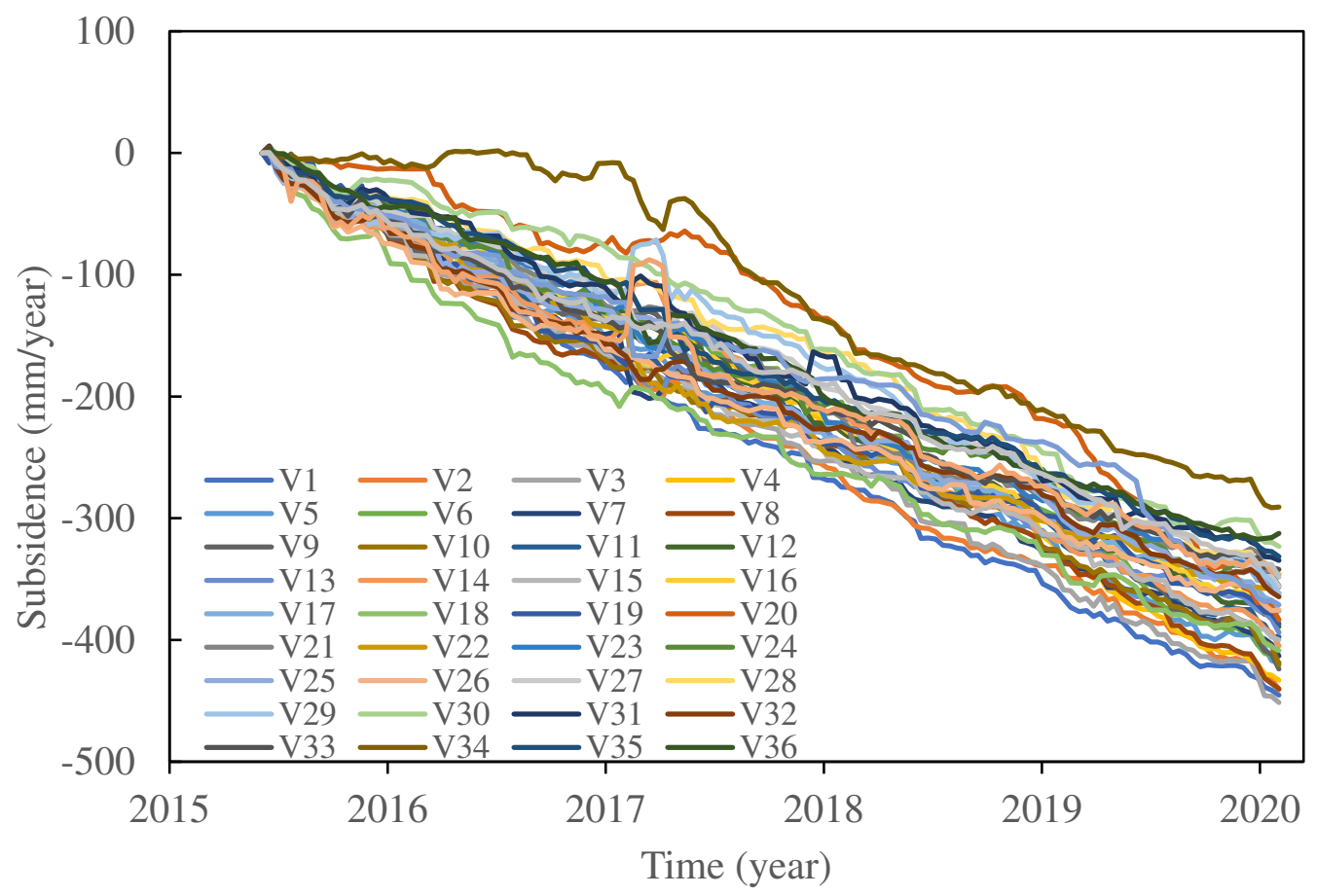

(b)

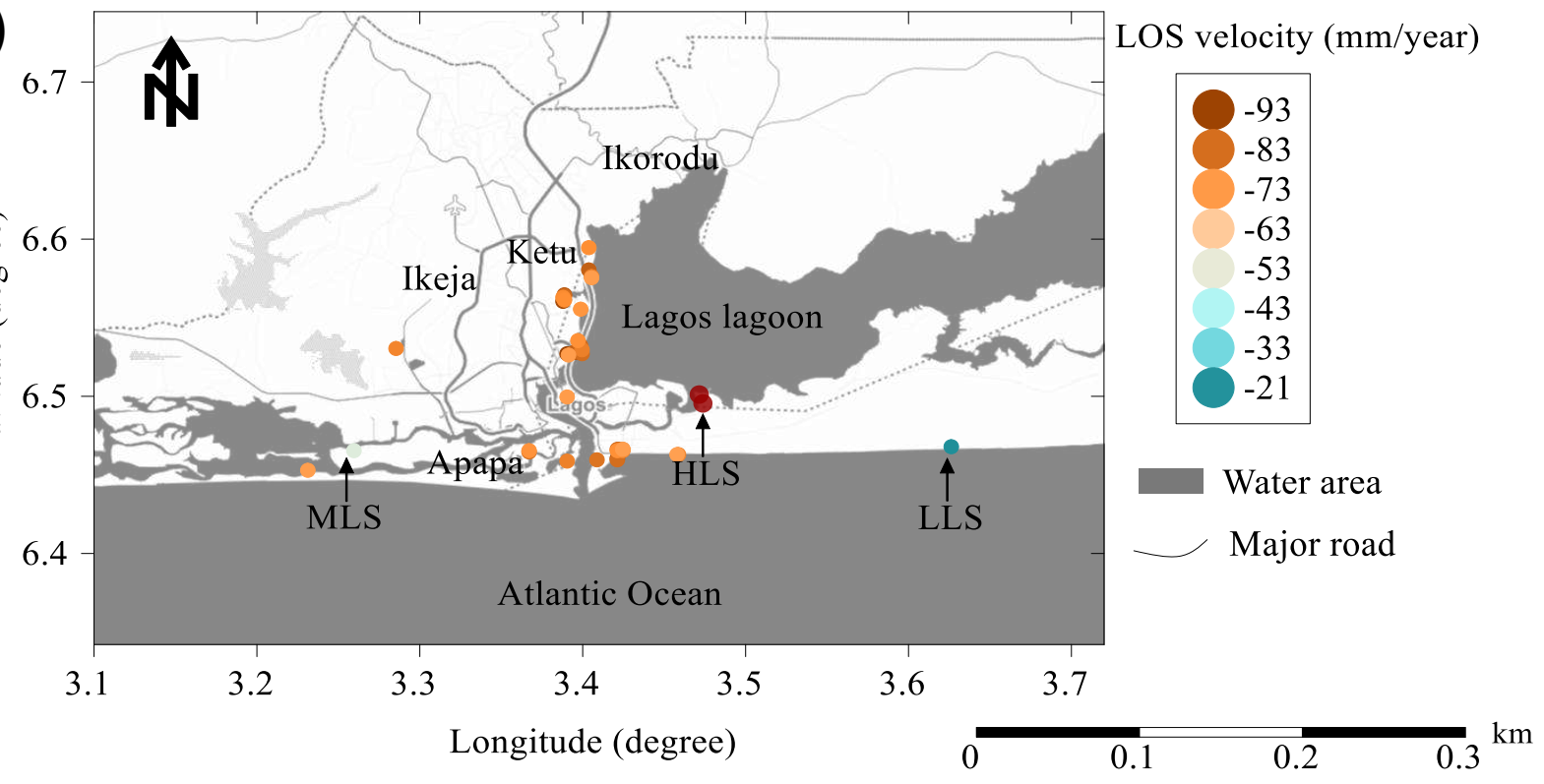


Fig. 6: (a)- Time series evolution of mean LOS land subsidence. V1 to V36: top highest subsidence points, with V1 (HLS1) as the point of highest subsidence rate. (b): locations of selected sites for wavelet analysis and areas undergoing rapid land subsidence. Black arrows pointing to the selected sites wavelet analysis.

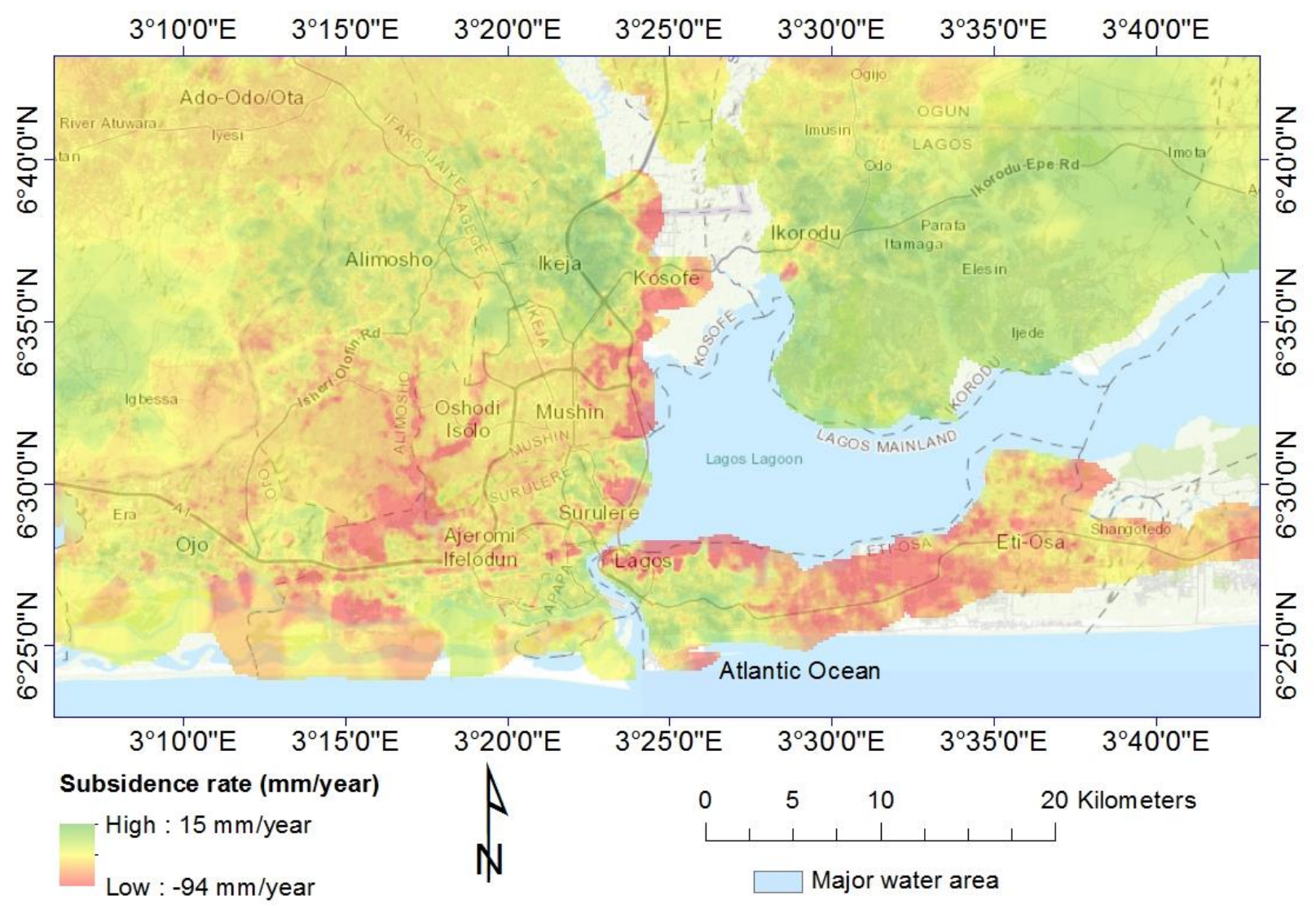

Fig. 7 Cumulative subsidence map for the study area acquired from Sentinel-1 data during 2015-2019. The background is open street map (OSM)

\subsection{Continuous wavelet-based analysis of LOS displacement}

The CWT describes the distribution of a frequency component of a signal in relation to time (Tomás et al., 2016). The land subsidence time series and groundwater level changes time series were subjected to continuous wavelet transform analysis to reveal the pattern of periodicity in each time series. Three subsidence sites were selected, all of which corresponded to varying land subsidence rates (high, moderate, and low). The acronyms HLS1, MLS, and LLS denote the sites of the highest land subsidence (HLS1), medium land subsidence (MLS), and lowest land subsidence (LLS), respectively. Furthermore, the terms HLS2, HLS3, and HLS4 are used to denote three other sites next to the highest subsidence rates, respectively. The CWT of land subsidence, along the LOS for the selected sites, is shown in Fig. 8. At HLS, the land subsidence time series generally indicates low power within the 5\% significance level and moderate power outside the 5\% significance level, suggesting that no periodic signal presents high power above the 5\% significance level 
and low magnitudes of vertical ground motion oscillations (Fig. 8a). The CWT power of the subsidence time series from MLS and LLS is shown in Figs. 8b and 8c, and has an 8-48 month band in the period from 2016 to 2018 . However, for the MLS site, the power is quite low, and thus, there is low power above the $5 \%$ significance level for the entire study period. In general, for HLS and MLS sites, the powers are relatively low, and thus there is no high power above the 5\% significance level for the entire study period. Fig. 9 shows the CWT of groundwater level change time series. As can be seen in the figure, all sites have commonly high positive values of the wavelet power spectrums at the $12-24$ month band and 32-48 month band in the period from mid-2015 to mid-2016 and late 2015 to early 2016 , respectively. This finding suggests that groundwater seasonality is periodically affected by groundwater abstraction and/or precipitation. Groundwater level changes time series scalograms show significant periodicities with power between 8-16 during the period of mid-2015 and mid-2016, which suggests seasonal groundwater level changes at the study sites. In general, the scalograms for the three sites appear similar. A possible explanation for this result can be attributed to the fact that the GRACE measures groundwater on a regional scale.

\subsection{XWT and WTC result}

The plot of the CWT modulus of a signal as a function of time and frequency is known as a scalogram. Generally, in scalograms, a thick contour and a thinner black line represent the 5\% significance level against the red noise and the cone

of influence (COI), respectively. The areas outside the COI are depicted with lighter shadows and can be inaccurate for signal analysis due to the edge effect. Wavelet power spectrum (WPS) is the energy distribution of the time series for an objective wavelet scale and time domain. Warm colors indicate high power, while low power is indicated by cold colours. The direction of the arrows shows the relative relationship between the two time series. The right-pointing arrow indicates in-phase (or a positive correlation), and the left-pointing arrow implies anti-phase (or a negative correlation). While a direct descendant arrow signifies that land subsidence leads soil moisture/groundwater level changes by $90^{\circ}$, the upright arrow signifies that soil moisture/groundwater level changes lags behind land subsidence by $90^{\circ}$. 

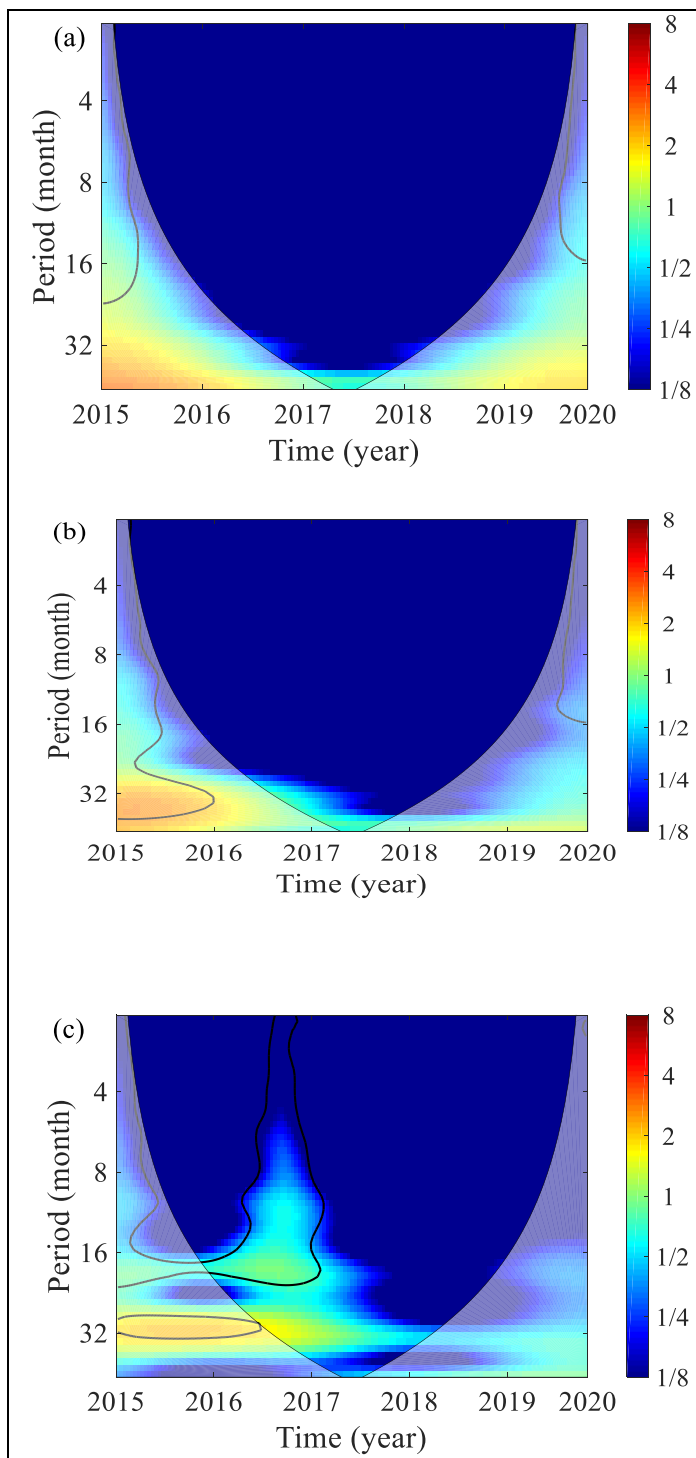

Fig. 8 CWT of mean Sentinel-1 derived land subsidence along the LOS direction for the three selected sites: (a) HLS1; (b) MLS; (c) LLS
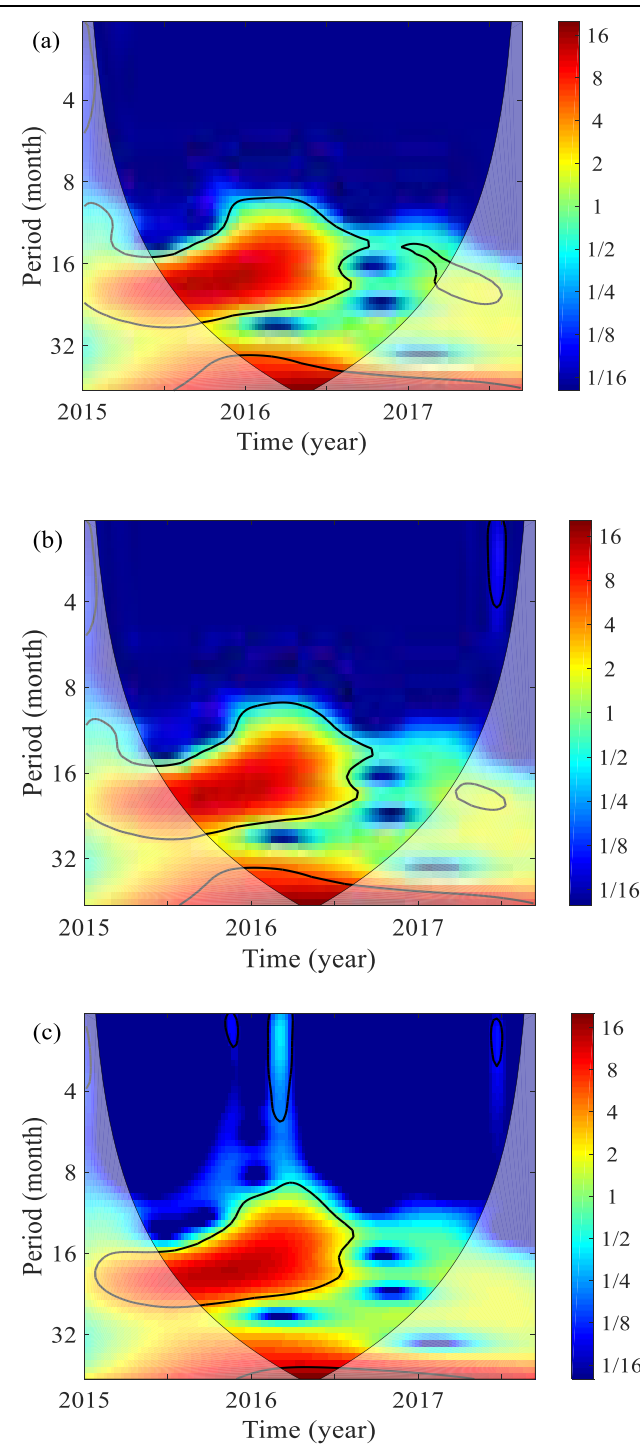

Fig. 9 CWT of GRACE derived groundwater level changes for the three selected sites: (a) HLS; (b) MLS; (c) LLS

\subsubsection{XWT and WTC analyses of land subsidence and groundwater level changes}

In this section, the relationship between land subsidence and groundwater level changes is investigated through XWT and WTC analyses. Both XWT and WTC analyses are useful tools for checking the proposed relations between two time series. While the XWT tool allows the identification of common power, WTC tools allows the identification of relative phase in time-frequency space. The GRACE-derived groundwater data between 2015 and mid-2017, and Sentinel-1 derived land subsidence from 2015 to 2019 were analysed. It is important to note that XWT and WTC analyses for subsidence data and groundwater data only cover from 2015 to 2017 because that was the period subsidence time series and groundwater time series temporally overlap for our study area. Before performing the wavelet analysis, linear 
interpolation was performed on the groundwater time series. As GRACE/GLDAS-derived groundwater data are averaged monthly (30 days temporal gap) and Sentinel-1 data have 12 days temporal gap, the groundwater time series data have to be interpolated in order to reduce the temporal gap to 12 days and make the two time series data to have equal temporal gap.

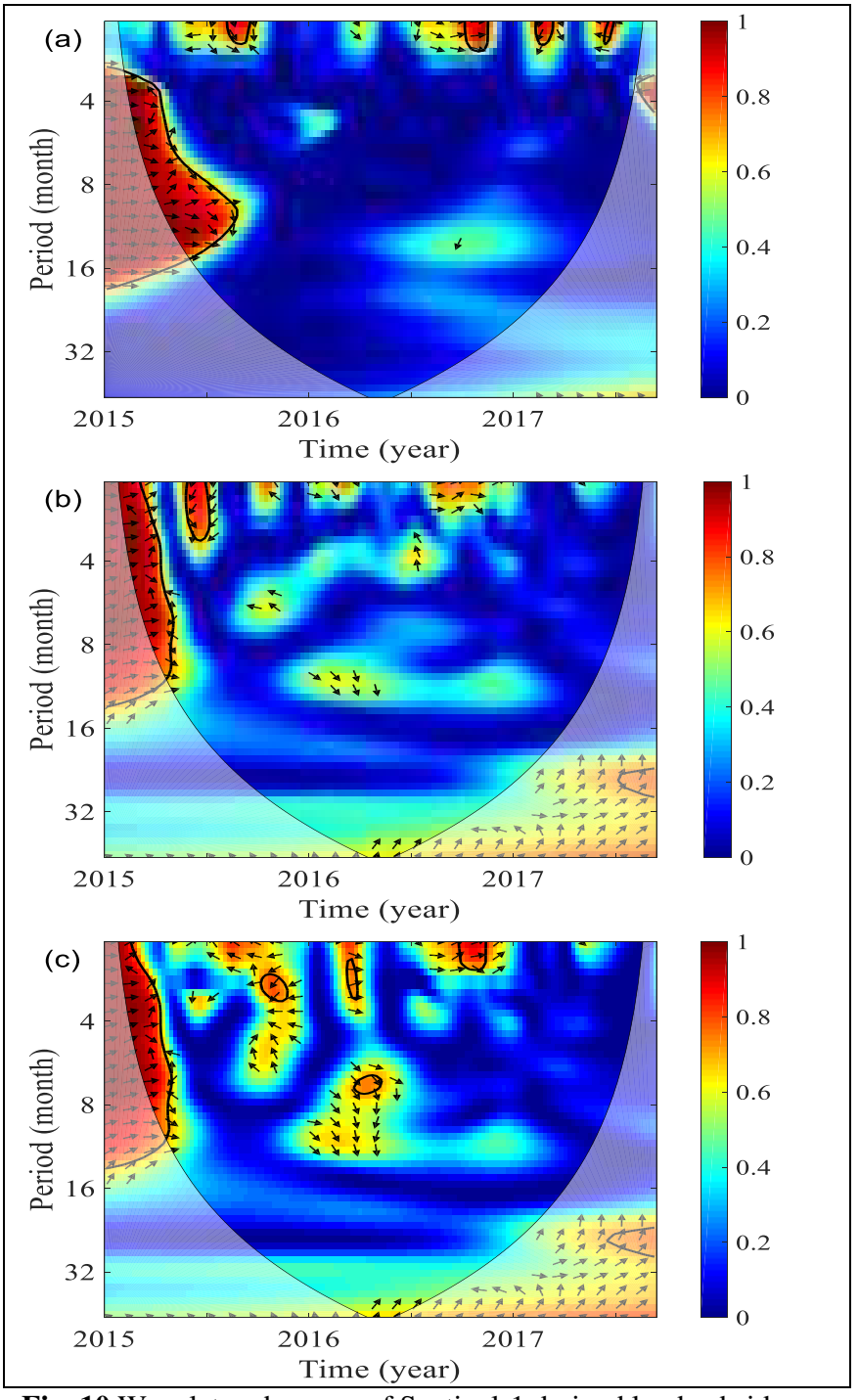

Fig. 10 Wavelet coherence of Sentinel-1 derived land subsidence along LOS and GRACE-derived groundwater level changes for the three selected sites. The relative phase relationship is indicated as arrows. (a)-(c) corresponds to sites HLS1, MLS, and LLS, respectively
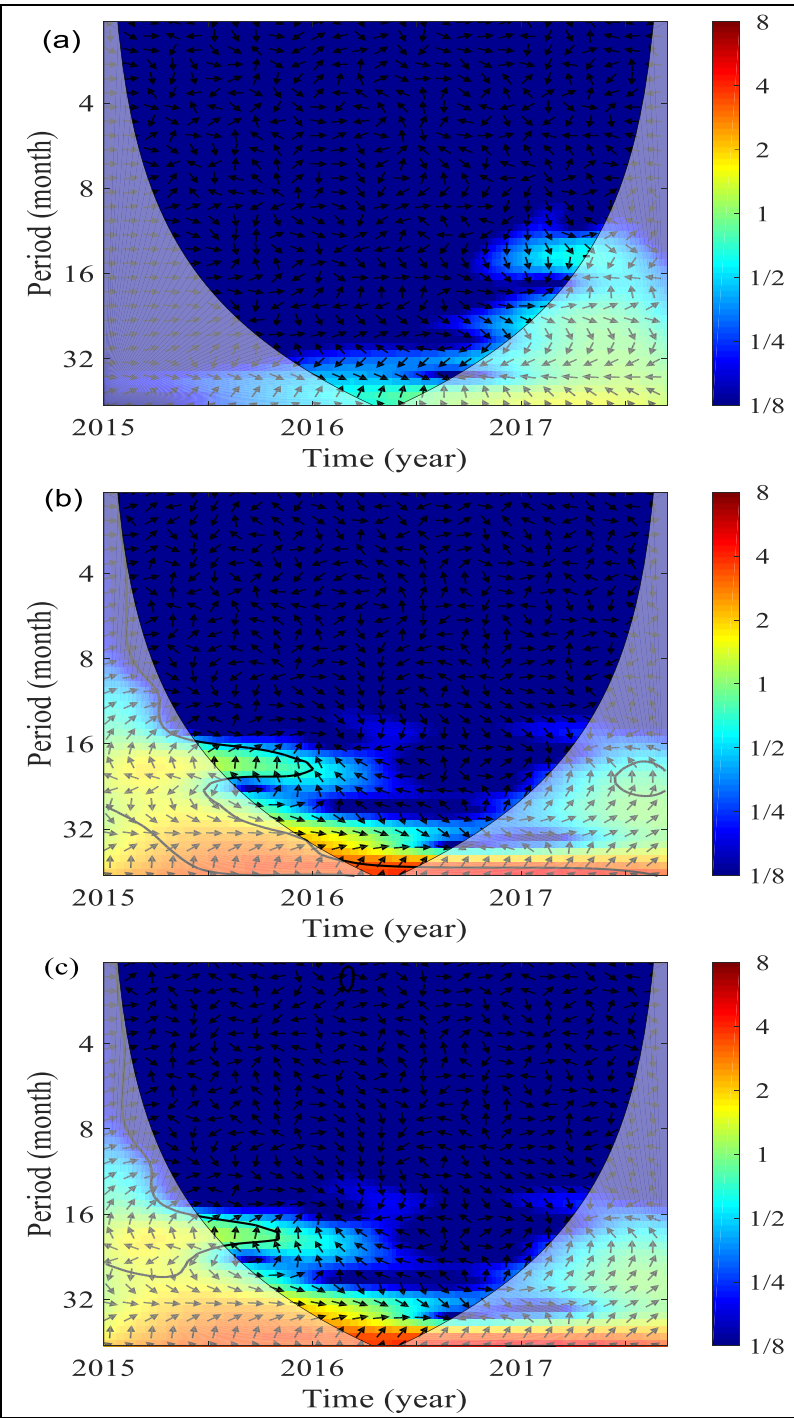

Fig. 11 Cross wavelet transform of Sentinel-1 derived land subsidence along LOS and groundwater level changes for the three selected sites. The relative phase relationship is shown as arrows. (a)-(c) corresponds to sites HLS1, MLS, and LLS, respectively

Figs. 10 and 11 depict the WTC and XWT for the Sentinel-1 derived land subsidence and groundwater level time series at the three selected sites, respectively. The statistical significance level of the WTC was computed based on Monte Carlo technique. WPS describes the spread of a frequency component as a time function which is used to identify the significant coherence between land subsidence time series and groundwater level changes time series. The arrows indicate the 
relative phase relationship vector, with in-phase pointing towards the right and anti-phase pointing towards the left. The land subsidence leads groundwater by $90^{\circ}$ pointing straight down, indicating the phase difference between the land subsidence and groundwater level changes. Inspection of the WTC scalegrams (Fig. 10) indicates that there were more areas with higher power above the 5\% significance level. Additionally, there was a significant variation in the phase relationship between land subsidence and groundwater level changes in different periods. In Fig. 10, a significant high power was observed for a period ranging between two months and four months. For all the three sites, the link between both variables appears to be close to anti-phase. As can be seen in Fig. 10a, land subsidence and groundwater level changes were in-phase with substantial common power in the two month band in early 2017 , but were anti-phase between June 2010 and November 2010. In Fig. 10b, a significant common power was observed up to the five month between mid-2015 and mid-2017. However, there was significantly low power observed around mid-2016. At the LLS site, several areas revealed significant coherence between land subsidence and groundwater level changes time series up to the ten month band in several periods, all above the 5\% confidence level. Generally, the results showed insignificant common powers in the three study sites. In Fig. 11, a relatively low common power in the 6-12 month band from late 2015 to early 2016 is found above the 5\% significance level, as shown in Fig. 11b and c, suggesting the possibility of other triggers of land subsidence asides groundwater level variation. However, Fig. 11a, shows that the observed low power is outside the $5 \%$ confidence interval.

\subsubsection{XWT and WTC analyses of land subsidence and soil moisture}

This section presents the relationship between land subsidence and soil moisture as analysed through XWT and WTC. Monthly averaged soil moisture data were obtained from GLDAS and interpolated in order to have a uniform temporal gap with the Sentinel-1 derived land subsidence. Figs. 12 and 13 show the result of WTC and XWT analysis between land subsidence time series and soil moisture time series for the selected sites, respectively. At HLS (Fig. 13a), XWT reveals a region within the 95\% confidence level, yet with low power, between 2016 and mid-2018, where the phase arrows indicate a shift between land subsidence and soil moisture. However, WTC (Fig. 12a) shows regions with significant coherence within the $5 \%$ confidence interval between land subsidence and soil moisture, but with common low power (approximately 0.6-1.0) in several periods and phase arrows pointing in varying directions. This is suggestive of the presence of both local correlation and anti-correlation. 

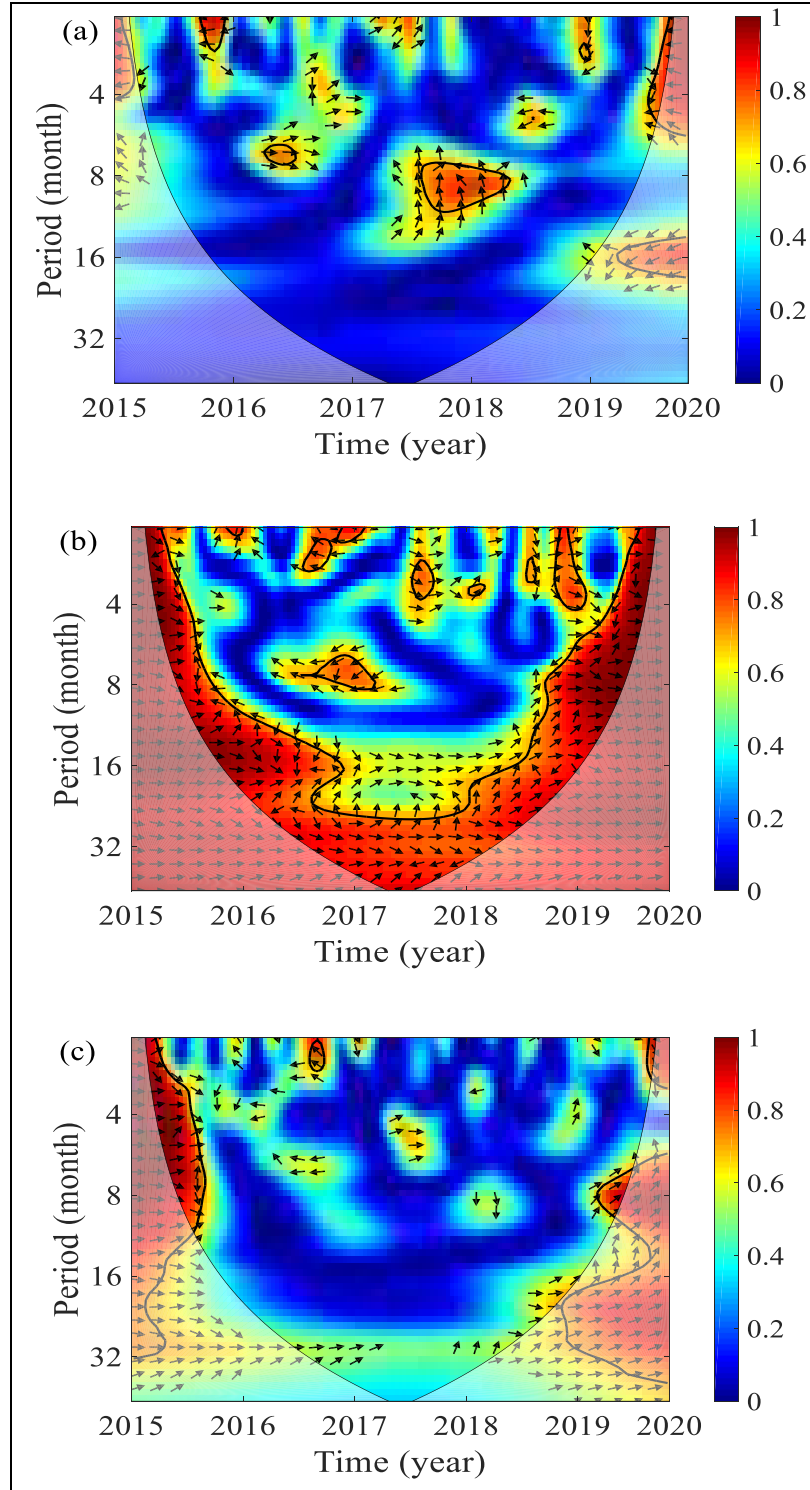

Fig. 12 Wavelet coherence of average land subsidence along LOS and soil moisture for the three selected sites. The relative phase relationship is indicated as arrows. In-phase pointing right while anti-phase pointing left. The land subsidence lagging soil moisture changes by $90^{\circ}$ pointing straight down: (a)-(c) correspond to HLS1, MLS, LLS, respectively
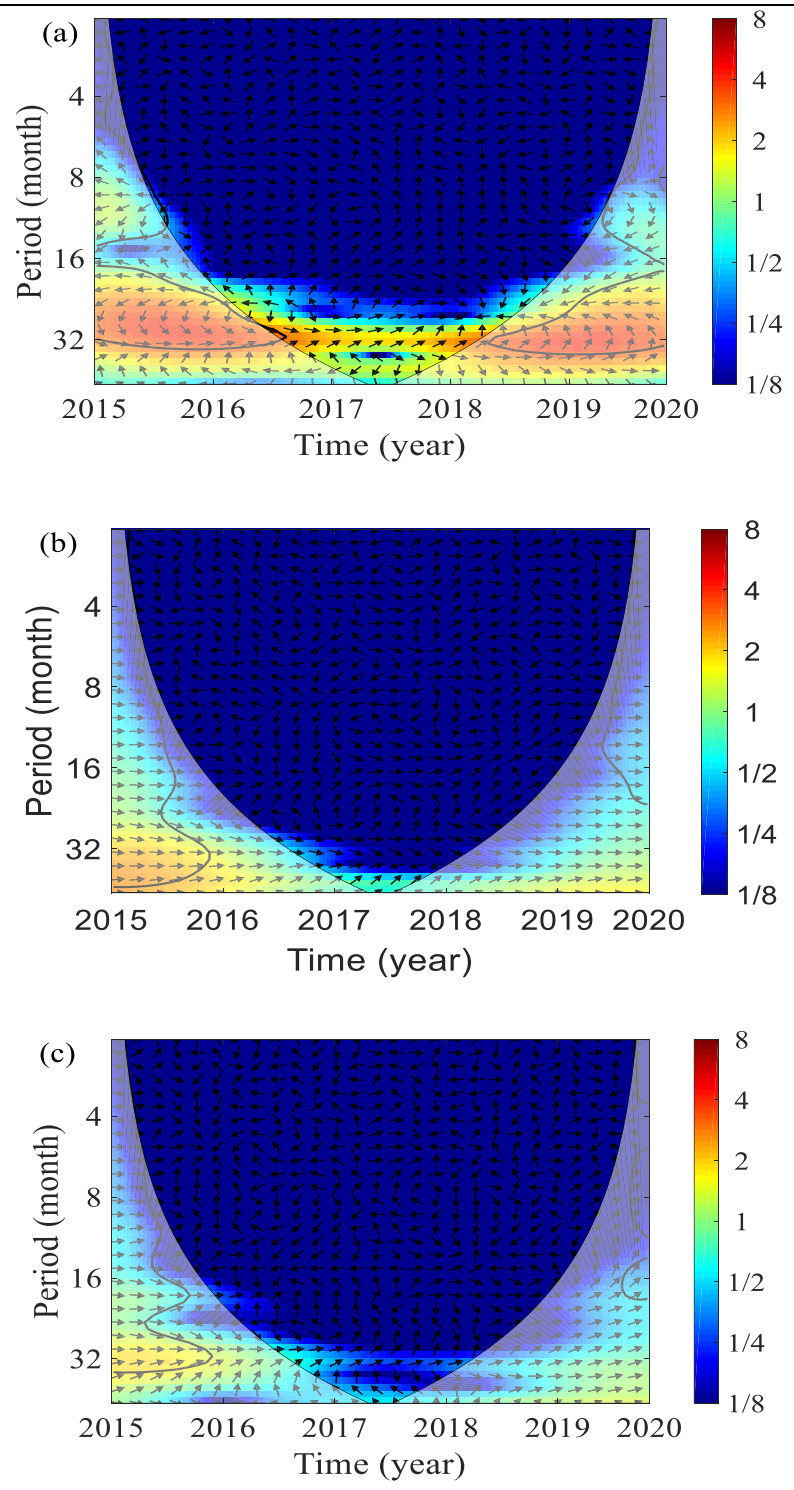

Fig. 13 Cross wavelet transform of average land subsidence along LOS and soil moisture for the three selected sites. The relative phase relationship is indicated as arrows. In-phase pointing right while anti-phase pointing left. The land subsidence lagging soil moisture by $90^{\circ}$ pointing straight down: (a)-(c) correspond to HLS1, MLS, LLS, respectively 
Between 2016 and 2017, the phase arrows point rightward, indicating a correlation between the two time series; and between 2017 and mid-2018, the phase arrows point upward, reflecting the presence of time lag between the two time series. Fig. 12b and Fig. 13b show the XWT and WTC of land subsidence and soil moisture, respectively, at the MLS site. Fig. 12b reveals high common power between land subsidence and soil moisture, approximately in the 12-month period, for the entire study period. WTC also indicates that land subsidence and soil moisture are out-phase (phase shift $\sim 180^{\circ}$ ) in all regions with significant common power. However, in XWT, there is little or no periodic signal illustrating high power above the 5\% significance level (Fig. 13b). Within the $95 \%$ confidence interval, a significant coherence value is observed for the entire study period, with most phase arrows pointing rightward.

According to the wavelet analysis results of the LLS site, different regions with high power are demonstrated in WTC (Fig. 12c) at bands $0.5-1$. Similar to what is observed in the HLS site, the phase arrows are pointing in different directions, which indicates that land subsidence and soil moisture are in-phase between mid-2016 and mid-2018 at the period of 4-7 month and 30-32 month respectively. The out-phase occurred between 2016 and 2017 at periods 3-6. In general, comparing all subplots in Figs. 12 and 13, WTC reveals more regions with common high power than XWT. The reason why WTC can reveal regions characterised by significant coherence is because XWT requires fewer values of individual CWTs to compute high coherence, but signal periodicities in WTC rely only on the time-frequency patterns against the power of components in the CWT. The observed negative correlation in both figures suggests the presence of other triggering factors of land subsidence during the period of study. Another possible reason for the negative correlation may be due to the inability of GRACE satellite to provide accurate data for small basin groundwater monitoring.

\subsection{Possible triggering factors of land subsidence in Lagos}

As it was stated in Section 2 and in the introduction of this paper, the Lagos aquifer is predominantly coastal alluvial, surrounded by massive water body. Land subsidence in metropolitan Lagos is significantly on the increase as a result of the nature of its geological formation and the rising anthropogenic contributions. As Lagos' population expands drastically, there is a growing need to withdraw more groundwater for domestic, industrial, and municipal purposes, which will cause groundwater levels to drop considerably. The results of wavelet analysis suggested that groundwater abstraction and soil moisture are possible triggering factors of land subsidence in Lagos. Nevertheless, the study has identified that there are other triggering factors of land subsidence in our study area besides groundwater abstraction and soil moisture variability. As reported in other literature, these other factor may include hydrostatic load, hydrocompaction, and natural compaction of unconsolidated sediments (Abidin., 2015). However, further study needs to be conducted to ascertain these other causes of land subsidence in Lagos metropolis. 


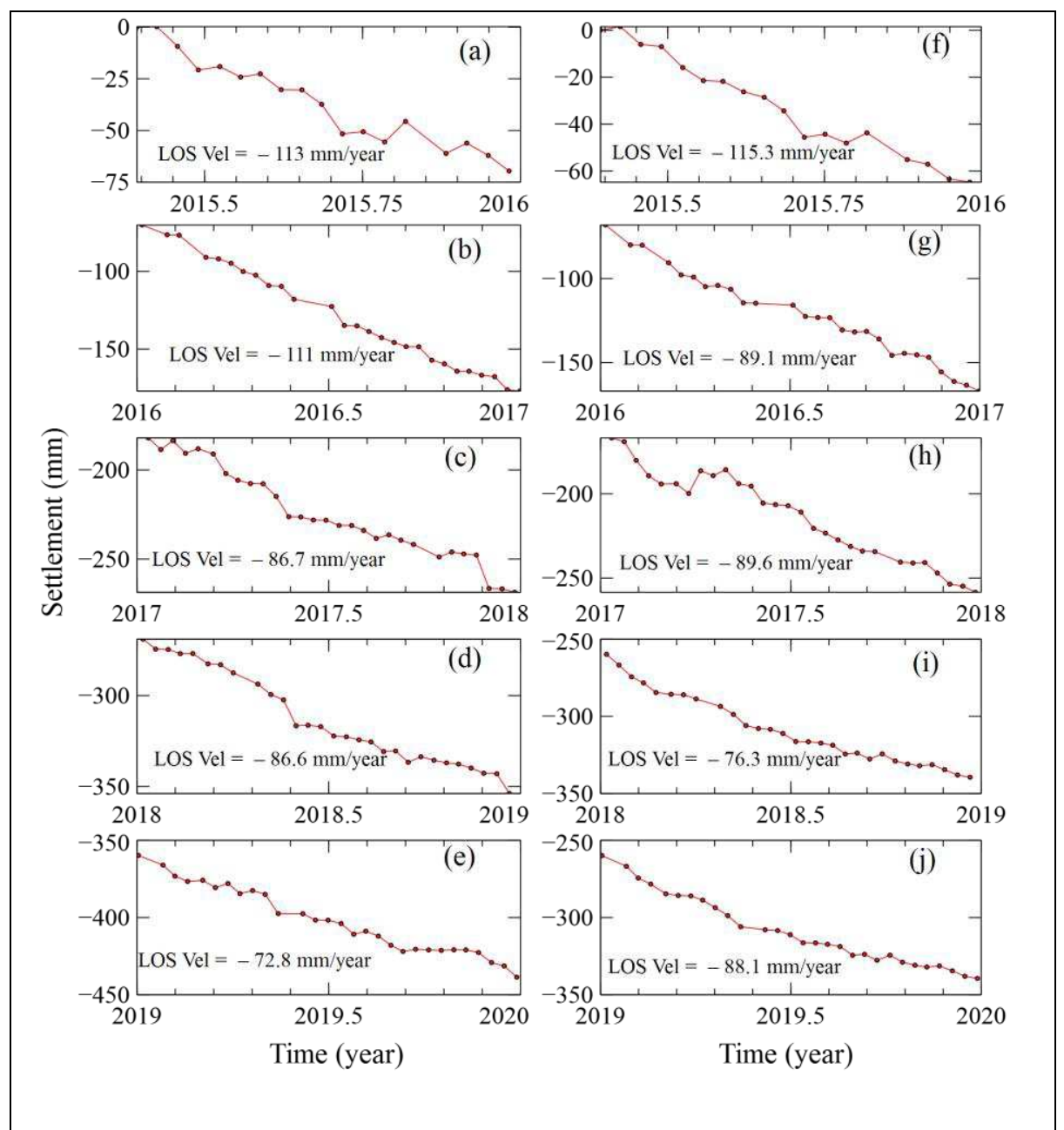

Fig. 14 Time series evolution of land subsidence per year. (a) - (e) corresponds to the subsidence time series at site HLS1 between 2015-2016, 2016-2017, 20172018, and 2018-2019, respectively. (f)-(g) is for site HLS2. (Ikuemonisan et al., 2021).

\subsection{Modelling results}

The result of wavelet analysis and reports from existing studies (Ikuemonisan et al., 2020) indicate that the magnitude and spatial distribution of land subsidence in metropolitan Lagos are controlled by a range of factors. These factors encompass groundwater abstraction, soil moisture content, compaction of unconsolidated sediments, and land use characteristics such as land reclamation. Consequently, this paper speculates that the empirical modelling approach would be suitable in this case to model and predict the future scenario of land subsidence in Lagos, Nigeria. Based on this speculation, the triple exponential smoothing algorithm was applied to the time-series data of the land subsidence and the prediction models were defined. The three key steps involved in the model implementation are parameters initialisation, optimisation, and model building. Smoothing parameters $\alpha, \beta$, and $\gamma$ were optimised using Excel solver, with minimum RMSE set as the condition for an optimal model. 

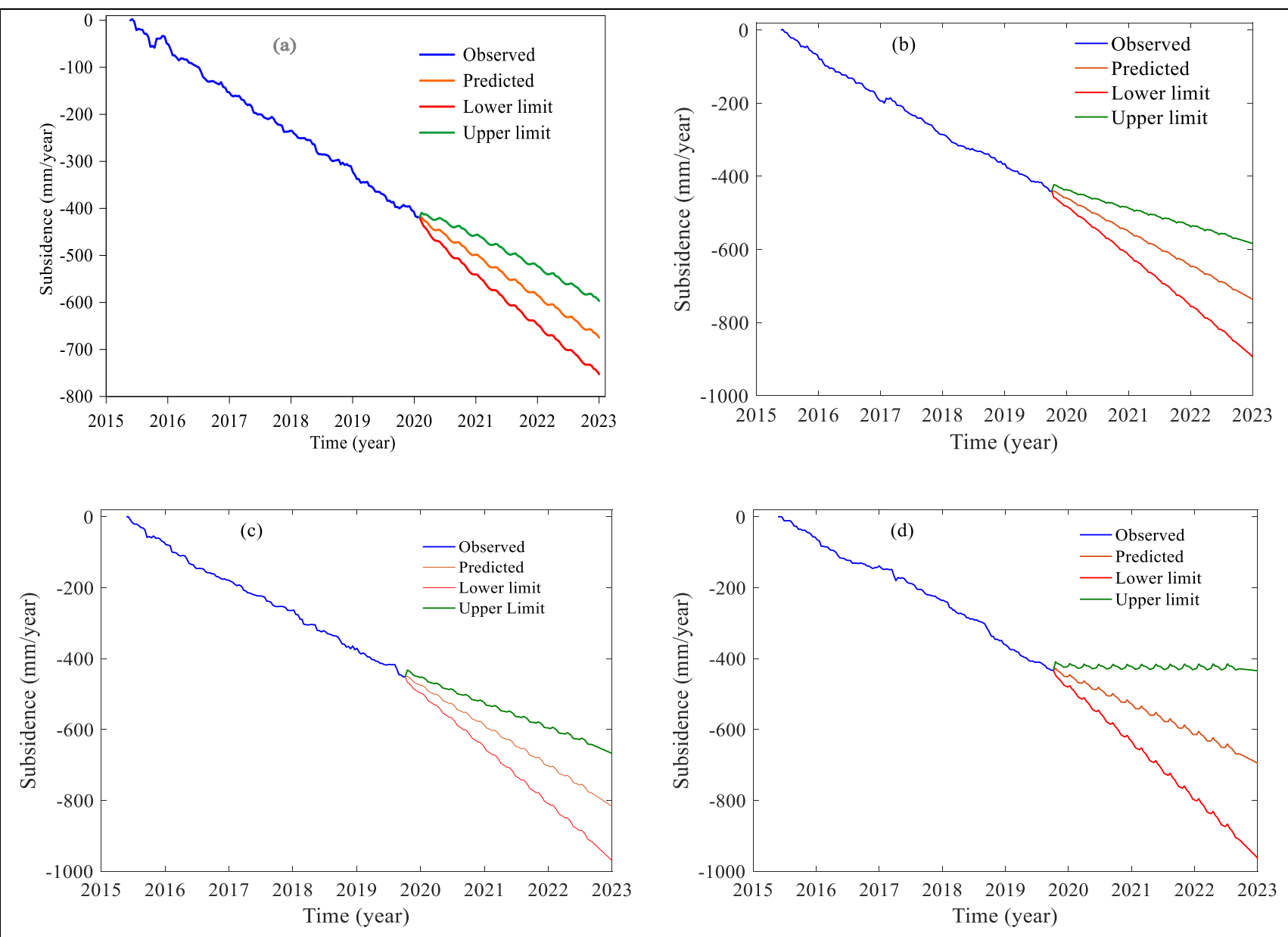

Fig. 15 Observed land subsidence and predicted land subsidence. (a) HLS1, (b) HLS2, (c) HLS3, and (d) HLS4

The Triple Exponential model predicts subsidence data based on the historical trend in Sentinel-1 derived land subsidence.

However, before the modelling, the stationarity of the input time series parameters was tested using descriptive statistics, including the meaning, variance, and autocorrelation. The result of the descriptive statistical analysis indicated the presence of varied mean, variance, and autocorrelation over time, confirming the state of non-stationarity of the subsidence time series. Fig. 14 shows the plot of the displacement-time series. For want of space, the yearly displacementtime series was presented for only two selected sites (HLS1 and HLS2). As seen in Fig. 14, there are variations in the annual mean LOS velocity, which confirms non-stationarity presence. The presence of non-stationarity suggests that there is a variation in the driving mechanisms of land subsidence in the area covered in the study. Consequently, before proceeding into the modelling scenario differencing technique was implemented in order to make the subsidence time series stationary. Four selected sites corresponding to points of highest subsidence rate were considered for the modelling.

Fig. 15 and Table 2 present the findings of the modelling Scenario. There are two established methods of triple exponential smoothing. These are additive method and multiplicative method. In this study, in comparison to the additive method, the multiplicative technique was found to present minimal error and was used to predict future scenarios. The 
computed smoothing parameters range between 0.10 and 0.41 for $\alpha, \beta$ values range between 0.01 and 0.30 , while the values of $\gamma$ lie between 0.20 and 0.30 . The selected combinations of smoothing parameters present minimal error and are considered as the best prediction model for the study area. Findings show that the lower the smoothing parameters, the smoother the line. In Fig. 15, results indicate that land subsidence in parts of Lagos metropolis will increase significantly. At HLS3, subsidence will reach $812 \mathrm{~mm}$ by the end of 2023, and the worst-case scenario (predicted lower bound) may be up to $958 \mathrm{~mm}$ and $945 \mathrm{~mm}$ by the end of 2023 at HLS3 and HLS4, respectively.

Table 2 Summary of model result

\begin{tabular}{rcccc}
\hline Site & HLS1 & HLS2 & HLS3 & HLS4 \\
\hline Alpha $(\alpha)$ & 0.10 & 0.15 & 0.25 & 0.41 \\
Beta $(\beta)$ & 0.01 & 0.21 & 0.15 & 0.30 \\
Gamma $(\gamma)$ & 0.20 & 0.30 & 0.30 & 0.21 \\
Predicted upper bound by the end of 2023 (mm) & 582.00 & 586.00 & 648.00 & 446.00 \\
Predicted subsidence by the end of 2023 $(\mathrm{mm})$ & 685.00 & 695.00 & 812.00 & 682.00 \\
Predicted lower bound by the end of 2023 $(\mathrm{mm})$ & 776.00 & 884.00 & 958.00 & 945.00 \\
\hline
\end{tabular}

\subsection{Model Validation}

Model validation is an important part of model formulation as it helps to understand the goodness of fit/accuracy. To quantitatively evaluate the goodness of fit of the proposed model and assess its performance, different accuracy indicators were used, which include mean absolute percentage error (MAPE), mean absolute deviation error (MAD), root mean square error (RMSE), and mean square error (MSE). Model validation was performed by comparing the subsidence obtained from the SBAS-InSAR analysis (observed subsidence) with the subsidence that was predicted by the triple exponential algorithm (predicted subsidence). The residuals indicating the model error were computed by subtracting the predicted from the observed subsidence. In the time series model validation, if the residuals were found to be normally distributed, it can be speculated that the quality of the model is sufficient enough to manage the three components of subsidence time series (cyclic, seasonality, and trend). The result of the accuracy indicators is presented in Table $\mathbf{3}$.

The normal probability plot of the residuals is shown in Fig. 16. As seen in all the subplots, the residuals are concentrated around the normal line, indicating normal distribution and implying a good fit. Further findings revealed that the residual between the actual and forecasted land subsidence varied between 4 and $8 \%$. The histograms of the model residual show normal distribution function, with error concentrating around zero. The scatter plot of the observed land subsidence versus 
predicted land subsidence show indicate good accuracy, with R-squared value ranged between 0.994 and 0.996, shown in Table 3. The estimated RMSE ranged between 7.920 and 9.720, which further confirm the accuracy of the proposed model. The triple exponential algorithm captures seasonality, trend, and level in a time series data.

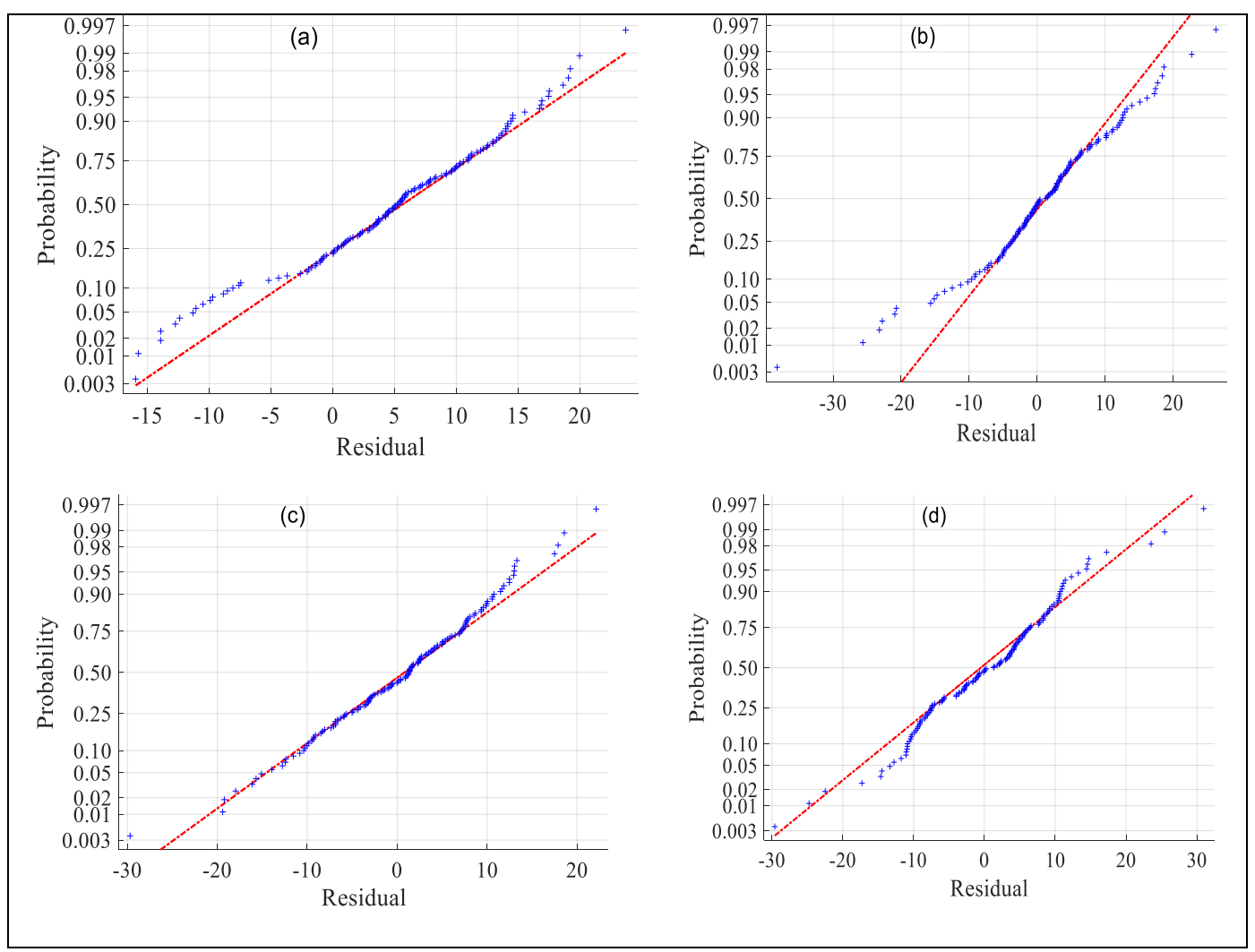

Fig. 16 Normal probability plot of residuals. (a) HLS1, (b) HLS2, (c) HLS3, and (d) HLS4

Table 3 Result of accuracy indicators

\begin{tabular}{rcccc}
\hline \multicolumn{1}{c}{ Site } & HLS1 & HLS2 & HLS3 & HLS4 \\
\hline MAPE (\%) & 0.010 & 6.430 & 19.610 & 16.050 \\
MAD (mm) & 3.910 & 7.320 & 6.960 & 7.690 \\
MSD (mm) & 42.650 & 91.780 & 75.940 & 92.380 \\
RMSE (mm) & 7.920 & 9.720 & 8.770 & 9.520 \\
R-squared & 0.996 & 0.994 & 0.995 & 0.994 \\
\hline
\end{tabular}

5

Conclusions

In this study, land subsidence that occurred between 2015 and 2019 due to various activities in metropolitan Lagos has been investigated by analysis of 135 Sentinel-1 data using the SBAS-InSAR technique, wavelet tools, and a triple 
exponential smoothing algorithm. Wavelet tools were used to investigate the physical correlation between land subsidence, and groundwater level changes and soil moisture variability. Findings revealed that the ground surface in the Lagos plain area has been under intense subsidence with a cumulative vertical displacement of approximately $425 \mathrm{~mm}$ between 2015 and 2019. Findings revealed a slight seasonal variation in the land subsidence time series but a significant variation in groundwater level changes and soil moisture at the monitoring sites. Findings further show that land subsidence in Lagos is partly controlled by groundwater level changes and soil moisture variation. This result suggests the possibility of other triggering factors of land subsidence apart from groundwater level fluctuations. Our proposed model indicates that maximum vertical cumulative land subsidence in parts of Lagos metropolis will reach $849 \mathrm{~mm}$ by the end of 2023. Evaluation of the proposed model indicates good accuracy. The highest residual is $8 \%$. The results of this study demonstrated that the SBAS-InSAR technique combined with wavelet transform and a triple exponential smoothing algorithm could be successfully used to analyse and model land subsidence.

\section{References}

Abidin HZ, Andreas H, Gumilar I, Sidiq TP (2015) Environmental Impacts of Land Subsidence in Urban Areas of Indonesia. Proceeding of FIG 2015 Sofia, 17-21.

Bagheri M, Dehghani M, Esmaeily A, Akbari V, (2019) Assessment of land subsidence using interferometric synthetic aperture radar time series analysis and artificial neural network in a geospatial information system: case study of Rafsanjan Plain, J. Appl. RemoteSens. 13(4): 044530, doi:10.1117/1.JRS.13.044530.

Ayolabi EA, Peters DY, (2005) Hydrochemical and electrical resistivity assessment of the impact of solid waste on the groundwater at Oke alfa refuse dumpsite, Lagos, Nigeria. Journal Science Eng., 12(1): 5936-5946.

Balogun II, Sojobi AO, Galkaye E (2017) Public water supplyin Lagos State,Nigeria: Review of importance and challenges, status and concerns and pragmatic solutions. Cogent Eng., 4, 1329776.

Berardino P, Fornaro G, Lanari R, Sansosti E (2002) A new algorithm for surface deformation monitoring based on small baseline deferential SAR interferograms. IEEE Trans. Geosci. Remote Sens., 40: 2375-2383.

Bermúdez JD, Segura JV, Vercheri E (2010) Bayesian forecasting with the Holt-Winters model. J Oper Res Soc 61:164171. 
Casu F, Elefante S, Imperatore P, Zinno I, Manunta M, De Luca C, Lanari R (2014) SBAS-DInSAR parallel processing for deformation time-series computation. IEEE J. Sel. Top. Appl. Earth Obs. Remote S, 7: 3285-3296.

Chen WF, Gong HL, Chen BB, Liu KS, Gao M, Zhou CF (2017) Spatiotemporal Evolution of Land Subsidence around a Subway Using InSAR Time-Series and the Entropy Method. Giscience \& Remote Sensing 54 (1): 789DOIdoi:10.1080/15481603.2016.1257297.

Cian F, Blasco JMD, Cabrera L (2019) Sentinel-1 for monitoring land subsidence of coastal cities in Africa using PSInSAR: a methodology based on the integration of SNAP and StaMPS. Geosciences, (9)124.

De Luca C, Cuccu R, Elefante S, Zinno I, Manunta M, Casola V, Rivolta G, Lanari R, Casu F (2015) An on-demand web tool for the unsupervised retrieval of earth's surface deformation from SAR data: The P-SBAS service within the ESA G-POD environment. Remote Sens., 7: 15630-15650.

Deng Z, Ke Y, Gong H, Li X, Li Z (2017) Land subsidence prediction in Beijing based on PS-InSAR technique and improved Grey-Markov model. Gisci. Remote Sens. 54: 797-818. doi:10.1080/15481603.2017.1331511.

Grinsted A, Moore JC, Jevrejeva C (2004) Application of the cross wavelet transform and wavelet coherence to geophysical time series, Nonlin. Process. Geophys., 11: 561-566.

Hill MB, Webb JF (1958) The topography and physical features of Lagos Harbour. Philos Trans R Soc Ser B, 241: 319333.

Hu J, Li ZW, Ding XL, Zhu JJ, Zhang L, Sun Q (2014) Resolving three-dimensional surface displacements from InSAR measurements: A review. Earth Sci. Rev., 133: 1-17.

Ikuemonisan FE, Ozebo VC (2020) Characterisation and mapping of land subsidence based on geodetic observations in Lagos, Nigeria. Geodesy Geodyn., 11 (2): 151-162. 10.1016/j.geog.2019.12.006.

Ikuemonisan FE, Ozebo VC, Olatinsu OB (2020) Geostatistical evaluation of spatial variability of land subsidence rates in Lagos, Nigeria, Geodesy and Geodynamics, 11(5): 316-327. https://doi.org/10.1016/j.geog.2020.04.001.

Ikuemonisan FE, Ozebo VC, Olatinsu OB (2021)Investigating and modelling ground settlement response to groundwater dynamic variation in parts of Lagos using space-based retrievals,Solid Earth Sciences 6(2): 95-110, doi.org/10.1016/j.sesci.2021.03.001 
Kampsax-Kruger and Sshwed Associates. Underground Water Resources of the Metropolitan Lagos, Final Report to Lagos State Ministry of Works, 1977. p. 170.

Landerer FW, Swenson SC (2012) Accuracy of scaled GRACE terrestrial water storage estimates. Water Resources Research, Vol 48, W04531, 11 PP, doi:10.1029/2011WR011453.

Longe EO, Malamo S, Olorunniwo MA (1987) Hydrogeology of Lagos metropolis. J Afr Earth Sci., 6(2): $163-174$.

Natural Environment Research Council (NERC) (2003) Groundwater Quality. British Geological Survey, Nigeria. http://www.wateraid.org/documents/plugin documents/nigeriagroundwaterweb.pdf.13/.

Olatinsu OB, Oyedele KF, Ige-Adeyeye AA (2019) Electrical resistivity mapping as a tool for post-reclamation assessment of subsurface condition at a sand-filled site in Lagos, southwest Nigeria. SN Appl. Sci., p. 24. $10.1007 / \mathrm{s} 42452-018-0028-5$.

Olowofela JA, Akinyemi OD, Ogungbe AS (2012) Application of electrical impedance tomography (EIT) in the investigation of the impact of solid waste leachate contaminant plumes on groundwater. Academia Arena, 4(6): 37-47. http://www.sciencepub.net.

Oyeyemi KD, Aizebeokhai AP, Oladunjoye MA (2015) Integrated and geochemical investigations of saline water intrusion in a coastal alluvial terrain, Southwestern Nigeria. Int. J. Appl. Environ. Sci. 10 (4): 1275-1288.

Rodell MPR, Houser U, Jambor J et al. (2004) The Global Land Data Assimilation System. Bulletin of the American Meteorological Society, vol 85 (3), pp 381-394.

Scifoni S, Bonano M, Marsella M (2016) On the joint exploitation of long-term DInSAR time series and geological information for the investigation of ground settlements in the town of Roma (Italy). Remote Sensing of Environment, 182: $113-127$.

Shrestha PK, Shakya NN, Pandey VP, Birkinshaw SJ, Shrestha S (2017) Model-Based Estimation of Land Subsidence in Kathmandu Valley, Nepal. Geomatics, Natural Hazards and Risk. https://doi.org/10.1080/19475705.2017.1289985.

Tomás R, Li Z, Lopez-Sanchez JM, Liu P, Singleton A (2016) Using wavelet tools to analyse seasonal variations from InSAR time-series data: a case study of the Huangtupo landslide. Landslides, 13: 437-450. https://link.springer.com/article/10.1007\%2Fs10346-015-0589-y. 
Terrence C, Compo GP (1998) A practical guide to wavelet analysis. Bulletin of the American Meteorological Society 79: 61-78. doi: 10.1175/1520-0477(1998)079<0061:apgtwa>2.0.co;2.

Yang Q, Wang Y, Zhang J, Delgado JA (2017) Comparative study of shallow groundwater level simulation with three time series models in a coastal aquifer of South China. Appl Water Sci, 7: 689-698. https://doi.org/10.1007/s13201-015$\underline{0282-2}$.

Zeitoun DG, Wakshal E (2013) The Subsidence Phenomenon Throughout the World. In Land Subsidence Analysis in Urban Areas: The Bangkok Metropolitan Area Case Study; Springer: Dordrecht, The Netherlands, 9-23. ISBN 978-94007-5506-2.

Zhang Y, Liu Y, Jin M, Jing Y, Liu Y, Liu Y, Sun W, Wei J, Chen Y (2019) Monitoring Land Subsidence in Wuhan City (China) using the SBAS-InSAR Method with Radarsat-2 Imagery Data. Sensors, (19) 743.

Zhou L, Guo J, Hu J, Li J, Xu Y, Pan Y, Shi M (2018) Wuhan Surface Subsidence Analysis in 2015-2016 Based on Sentinel-1A Data by SBAS-InSAR. Remote Sens., 9: 982.

\section{Funding}

No formal funding received for this research

\section{Conflicts of interest/Competing interests}

The authors declare no conflict of interest

\section{Availability of data and material}

Not applicable

\section{Code availability}

Not Applicable

\section{Acknowledgments}

GRACE land data are available at http://grace.jpl.nasa.gov, supported by the NASA MEaSUREs Program. GLDAS data were received from "http://grace.jpl.nasa.gov", which used the "Goddard Earth Sciences Data and Information Services 
Center". Sentinel-1 data were processed in the framework of the GEP initiative supported by the ESA. We thank the entire GEP team, particularly Hervé Caumont, for all the supports they provided. The contributions of three anonymous reviewers are greatly appreciated. Their contributions have greatly improved the quality of this paper. The authors thank the Editor for his thoughtful evaluation of this paper. 